\title{
Über den Ursprung und die Bedeutung der Lehre Isaac Newtons vom absoluten Raum
}

\author{
Von Markus Fierz, Basel
}

\section{Einleitung}

Uns allen ist es wohl deutlich, daß die Naturwissenschaften, und die aus ihnen entsprungene Teschnik, schicksalsbestimmende Mächte unserer Zeit geworden sind. Sie unterscheiden unser Leben und Denken wesentlich von dem aller früheren Zeiten. Wenn aber Segnungen und Schrecken dieser neuen Mächte jedermann gegenwärtig sind, so sind uns die geistigen Grundlagen, denen sie ihr Dasein verdanken, viel weniger klar.

In der Entwicklung, die in den letzten dreihundert Jahren das naturwissenschaftlich-technische Zeitalter heraufgeführt hat, hatte die Physik immer wieder eine führende Rolle. Indem wir darum die Entstehung eines für die Physik grundlegenden Begriffs verfolgen, indem wir die philosophischen Ideen aufspüren, die seine Entstehung begleitet haben, hoffen wir auch, etwas vom Geist der Naturwissenschaften fassen zu können. Unser Gegenstand soll darum der Begriff des physikalischen Raumes sein, wie er durch Newton formuliert worden ist. Und wenn auch, seit der Relativitätstheorie, sich unser Raumbegriff von demjenigen Newtons in mancher Hinsicht unterscheidet, so bedeutet das doch zum Schluß nur seine letzte und konsequente Weiterentwicklung.

IsaAC Newton wurde, als nachgeborener Sohn, im Dezember 1642 auf dem Landgut seiner Eltern geboren. Mit achtzehn Jahren bezog er die Universität Cambridge, die für über dreißig Jahre seine Heimat werden sollte. Hier führten die Gelehrten ein fast klösterliches Leben. Die Universitätslehrer waren nicht nur alle Geistliche, es war ihnen auch verboten zu heiraten ${ }^{1}$. In dieser Umgebung erwarb er sich die Kenntnisse der damaligen Wissenschaft, wozu nicht nur Mathematik und Physik gehörten, sondern ein tiefes Eindringen in Theologie und Kirchengeschichte. Ins Jahr 1666, das ist die Zeit der letzten Pestepidemien in England und des großen Brandes von London, fallen Newtons erste große mathematische Entdeckungen. Sein Lehrer IsAAC BARRow ${ }^{2}$ war davon so beeindruckt, daß er 1669 zu-

${ }^{1}$ Siehe z. B. G. M. Trevelyan, English Social History, S. 184 (New York 1942).

${ }^{2}$ IsaAc Barrow (1630-1677) studierte in Cambridge und las damals vor allem «Lord Verulam, Monsieur des Cartes and other great Wits of the last Age» - so heißt es in der 
gunsten Newtons von seinem Lehrstuhl zurücktrat, um sich wieder ganz theologischen Studien zu widmen.

Newton wirkte nun fast dreißig Jahre als Professor in Cambridge. Von der Verpflichtung, Geistlicher zu werden, wurde er 1675 durch königliches Dekret entbunden. Noch mehr als sein Lehrer neigte er nämlich zu Ansichten, die dem Kirchenglauben widersprachen; insbesondere hielt er das Dogma der Dreieinigkeit für eine von den Theologen ersonnene, unbiblische Lehre. Wenn er nun auch seine abweichenden Meinungen geheim hielt, Geistlicher zu werden verbot ihm sein Gewissen.

1672 veröffentlichte er seine optischen Entdeckungen. 1687 erschien sein monumentales Hauptwerk, die Philosophiae naturalis Principia mathematica. In diesem legte er die Grundlagen der allgemeinen Mechanik und zeigte, wie mit ihrer Hilfe aus den von KePLer gefundenen Gesetzen der Planetenbewegung das Gravitationsgesetz hergeleitet werden kann. Überdies war es ihm möglich, die beobachteten Abweichungen von den Gesetzen Keplers als Folge der gegenseitigen Anziehung der Planeten quantitativ zu erklären. Desgleichen gelangte er zu einem Verständnis von Ebbe und Flut. Um die vielfältigen physikalisch-theoretischen Probleme, die sich in diesem

Biographie, die seinen theologischen Werken vorangestellt ist (The Works of the learned Isaac Barrow D.D. published by his Grace Dr. John Tillotson, late Archbishop of Canterbury, London 1716). Als überzeugter Royalist glaubte er, er eigne sich, den Zeitumständen entsprechend, nicht für den Kirchen- oder Staatsdienst. So entschloß er sich nur zögernd zum Studium der Theologie, was ja, als Fellow of Trinity, seine Pflicht gewesen wäre. Sein Zögern mag wohl noch andere als politische Gründe gehabt haben. Theologisch stand er nämlich im Verdacht, ein Arminianer zu sein, und er war mit Wніснсоте, einem der Begründer der platonischen Bewegung in Cambridge, befreundet. Seine Rechtgläubigkeit, insbesondere in bezug auf die calvinistische Prädestinationslehre, war somit zweifelhaft. Dies hatte auch zur Folge, daß seine Bewerbung um den Lehrstuhl für Griechisch, trotz Empfehlungen des Vorgängers und hoher Qualifikationen, abgelehnt wurde. Darum reiste er 1657 über Frankreich und Italien nach Konstantinopel, nicht ohne ein romantisches Abenteuer mit Seeräubern zu erleben. In Konstantinopel blieb er ein Jahr und studierte dort vor allem die Kirchenväter. Nach seiner Rückkehr nach Cambridge ließ er sich endlich zum Priester weihen. Die Restauration brachte für ihn günstigere Zeiten, und 1660 erhielt er den Lehrstuhl für Griechisch. 1663 stiftete Henry Lucas in Cambridge den ersten mathematischen Lehrstuhl. Barrow wurde dessen erster Inhaber (der heutige Inhaber ist P. A. M. DiRAC). Nach seinem Rücktritt zugunsten Newtons übte er durch regelmäßige Predigten, die freilich eher theologischen Vorlesungen gleichen, einen bedeutenden Einfluß auf die akademische Jugend aus. 1672 wurde er Master of Trinity, wodurch er auch das Recht erhielt zu heiraten. Darauf aber verzichtete er ausdrücklich. Als Theologe stand er dem berühmten J. Tillotson nahe, der auch seine Grabrede hielt. 
Zusammenhang boten, bewältigen zu können, waren neuartige mathematische Methoden notwendig: das ist die Differentialrechnung, die Newton aus den geometrisch-analytischen Ansätzen der damaligen Zèit entwickelt hatte. Ohne diese Art Mathematik ist uns heute theoretische Physik undenkbar.

Seine großen wissenschaftlichen Leistungen erwarben ihm einen weltweiten Ruhm. Sie zogen ihm aber auch manche Unannehmlichkeiten zu, da sich auch Widerspruch gegen seine Lehren erhob.

Newton war von je ein eher zurückgezogener, mißtrauischer und empfindlicher Mensch gewesen. Dazu kam, daß er seine Erkenntnisse und Gedanken als persönlichen Besitz betrachtete. Ungern gestand er anderen Forschern einen Anteil daran zu. Kritik und Zweifel an seinen Lehren erregten seinen höchsten Unwillen, und er reagierte so, wie wenn er selber leichtfertig, oder gar böswillig, angegriffen worden wäre. Schon nach der Veröffentlichung seiner optischen Arbeiten regten ihn die daraus entstehenden Diskussionen derart auf, daß er am liebsten allen weiteren Veröfentlichungen entsagt hätte, um nicht ein Sklave zu werden, sie zu verteidigen; so schrieb er dem Sekretär der Royal Society, Oldenburg. Und an Leibniz schrieb er, er sei derart von Diskussionen verfolgt worden, daß er seine Unklugheit tadle, die ihn einem Schatten nachjagen ließ und ihn um den so wesentlichen Segen seiner Ruhe gebracht habe.

Die Principia hat denn Newton auch nicht selber herausgegeben. Dies besorgte vielmehr sein Freund, der Astronom Halley. Kurz vor der Drucklegung entstand neuer Streit; diesmal mit Roвert Hooke, der, nicht ohne Recht, seine Verdienste um die Entdeckung der Gravitationsgesetzes gewürdigt wissen wollte. Newton war sehr erbost, und schrieb an Halley, die Wissenschaft sei eine derart streitsüchtige Dame, daß man, anstatt mit ihr zu verkehren, ebensogut Prozesse führen könnte. Er dachte daran, den astronomischen Teil seines Werkes ganz zu unterdrücken. Unter dem Titel De motu corporum wäre so ein sehr abstraktes Buch entstanden, das wohl nur wenige recht verstanden hätten, und Newton wären, wie er hoffte, weitere Diskussionen erspart geblieben.

Auch in späteren Zeiten sollte es zu solchen Streiten kommen. Der berühmteste ist derjenige mit LeIBNIz um die Priorität in der Erfindung der Differentialrechnung. Über Jahre, bis zu Leibniz' Tod, ja darüber hinaus, wurde mit größter hartnäckigkeit und wenig Gerechtigkeit gestritten.

In den Jahren nach der Veröffentlichung der Principia entwickelte sich das schon immer vorhanden gewesene Mißtrauen Newtons den Mitmen- 
schen gegenüber zu einer eigentlichen Krankheit. Er glaubte, man wolle ihn «durch Frauen oder auf andere Art in Verwirrung bringen», er konnte nicht mehr schlafen und kaum mehr essen, und er war sehr unglücklich. In seinem fünfzigsten Jahr erreichte dieser Zustand den Höhepunkt. Nachrichten davon drangen bis nach Frankreich und Deutschland. Die Gründe für seine Depression sind recht undurchsichtig und sicherlich komplex. Überarbeitung und eine tiefe Unzufriedenheit mit seiner wissenschaftlichen Tätigkeit, so paradox dies bei seinen Erfolgen klingen mag, mögen mitgewirkt haben. Schließlich gelang es ihm aber, die Krise zu überwinden, wobei die Freundschaft und das Vertrauen derer, die ihm nahestanden, gewiß viel halfen. Denn trotz seines schwierigen Charakters muß er auf seine Umgebung einen mächtigen Zauber ausgeübt haben, und er fand immer Freunde, die treu zu ihm hielten.

1696, wie zum Zeichen, daß nun die Krise endgültig überwunden sei, tat Newton einen entscheidenden Schritt. Er wendete sich vom akademischen Leben ab und übernahm die ihm angebotene Stelle eines königlichen Münzwardeins. Drei Jahre später wurde er Direktor des Münzamtes und versah diese angesehene und sehr hoch bezahlte Stellung bis kurz vor seinem 1727 erfolgten Tode.

Als Beamter des Königs lebte er in London. 1703 wurde er zum Präsidenten der Royal Society gewählt, und 1705 erhob ihn die Königin Anna in den Adelsstand - das erste Mal, daß einem Gelehrten diese Ehre widerfuhr.

Wissenschaftlich war er aber jetzt nicht mehr produktiv tätig. Vielmehr beschränkte er sich darauf, das wissenschaftliche Ansehen, das er als Professor in Cambridge erworben hatte, zu wahren. So gab er 1704 seine Optik heraus, die eine geschlossene und leicht lesbare Übersicht über das von ihm hier Erreichte bietet. 1713 folgte eine vermehrte und verbesserte Ausgabe der Principia. In diesen Arbeiten, wie auch in den gelehrten Kämpfen mit Leibniz, wurde er durch jüngere Gelehrte unterstützt, die ihm fast bedingungslos ergeben waren und alle ihre Kräfte zum Ruhme ihres verehrten Meisters einsetzten.

Newtons beide großen wissenschaftlichen Werke besitzen, wie wenn er sich dadurch vor jedem Angriff hätte schützen wollen, eine eigentümlich unpersönliche, monumentale Form. Was sich für eine solche Darstellung nicht eignete, veröffentlichte er entweder gar nicht, wie die meisten seiner mathematischen Entdeckungen, oder er gab ihm, wie dies im Anhang zur Optik geschieht, die unverbindliche Form von «Fragen», wo es dann schwierig ist, seine eigene, wirkliche Meinung zu erkennen. 
Dies gilt auch für seine Lehre von Raum und Zeit. Diese hat er zuerst in den Principia vorgetragen und später bei verschiedenen Gelegenheiten näher erläutert. Aber diese Erklärungen sind keineswegs so gehalten, daß der tiefere Sinn seiner Lehren durchaus verständlich würde. Sicher ist, daß er Raum und Zeit eine weit über die Physik hinausreichende, theologische und religiöse Bedeutung zuschrieb.

Schon sein rein physikalischer Raum-Zeit-Begriff ist scharfsinnigen Denkern, wie Leibniz und Berkeley, paradox vorgekommen. Seine theologischen Lehren, so vorsichtig er sie auch formulierte, erschienen überdies bedenklich, und seine Nachfolger haben ihn in diesem Punkte je länger desto weniger verstanden. Damit verloren sie aber auch das Problematische seiner Konzeption aus den Augen.

\section{Literatur zu Newton}

\section{Biographien:}

David Brewster, Memoirs of the Life, Writings and Discoveries of Sir J. Newton (Edinburgh 1854). Klassische Darstellung, die viel wertvolles Material, auch aus dem Nachlaß, enthält. Newton wird jedoch allzusehr als der nationale Heros dargestellt, seine Schattenseiten werden bemäntelt, und insofern ist das Werk veraltet.

Louis T. More, Isaac Newton. A Biography (New York 1934). Wohl die beste moderne Darstellung.

E. N. Da C. Andrade, Sir Isaac Newton (London 1954).

Sein Werk betreffend:

F. Rosenberger, Isaac Newton und seine physikalischen Prinzipien (Leipzig 1895).

H. W. Turnbull, Mathematical Discoveries of Newton (London 1945).

Samuel Horsley, Isaac Newton Opera quae exstant omnia, 5 Vol. (London 1779-1785).

Dies ist die einzige Gesamtausgabe der Werke und Briefe. Sie umfaßt aber nicht einmal alle schon damals gedruckten Schriften. Der Nachlaß ist nicht berücksichtigt.

Der Briefwechsel, der bisher nur teilweise ediert war, wird nun herausgegeben durch:

H. W. Turnbuld, Isaac Newton Correspondence, Vol. 1. 1661-1675 (Cambridge 1954). Der sehr umfangreiche Nachlaß ist größtenteils unveröffentlicht. Siehe hiezu:

Lord Keynes, Newton the Man (Trecentary Celebration, London 1946).

E. N. Da C. Andrade, Endeavour XII, S. 68 (1953).

\section{Die Aussagen Newtons über die Zeit, den Raum und die Schwerkraft}

Im Denken Isaac Newtons spielen Zeit, Raum und Schwerkraft eine besondere, bedeutsame Rolle. Denken wir an den physikalischen Sinn dieser Begriffe, so ist dies leicht begreiflich. $\mathrm{Da} ß$ sie aber eine geradezu religiöse 
Bedeutsamkeit haben sollten, das ist für uns viel weniger leicht verständlich. Das Verständnis wird noch erschwert, weil Newton eine besondere Scheu zeigte, seine geheimen Hintergedanken anderen zu offenbaren, weshalb seine wenigen Aussagen über diese Fragen oft dunkel oder zweideutig scheinen. Anderseits hat seine lakonische Art den Vorteil, daß es möglich ist, sich einen ziemlich umfassenden Überblick über das, was er ausgesagt hat, zu verschaffen.

In seinem Hauptwerk, den Philosophiae naturalis Principia mathematica (1687) hat er in einem langen Scholium ausführlich erläutert, was man unter dem «absoluten Raume» und der «absoluten Zeit» zu verstehen habe.

Er sagt dort, die absolute, wahre und mathematische Zeit fließe gleichmäßig in sich selber, ohne jede Beziehung auf irgend etwas außer ihr. Man könne sie auch die Dauer nennen. Die relative, scheinbare und gewöhnliche Zeit aber sei ein den Sinnen zugängliches und äußeres $\mathrm{Maß}$ jener Dauer, das man anstelle der wahren Zeit gebrauche.

Ganz entsprechend wird gesagt, daß der absolute Raum immer in sich, sich selber gleich und unbeweglich ruhe, ohne Beziehung auf irgend etwas außer ihm. Der relative Raum aber sei das Maß für irgend etwas Bewegliches, das von unsern Sinnen in Beziehung zu seiner Lage an den Körpern erkannt werde und das man gewöhnlich an Stelle des unbeweglichen Raumes setze, wie z. B. das Ausmaß eines irdischen oder himmlichsen Raumes, der durch seine Lage relativ zur Erde abgegrenzt wird.

Der absolute Raum wie die absolute Zeit seien gewissermaßen die Örter aller Dinge: in der Zeit folgt alles aufeinander, im Raume ist alles angeordnet. Daß sich diese primären Örter bewegen könnten, das sei absurd.

Es ist nicht schwer, einen theoretisch-physikalischen Grund zu finden, der Newton zu diesen Erklärungen veranlaßt hat. Wenn nämlich in der Mechanik auch einer gleichförmigen Translationsbewegung keine absolute Bedeutung zukommt, so hat doch die Beschleunigung, d. h. jede Abweichung von der gleichförmig-geradlinigen Translation, eine absolute Bedeutung. Man kann auch sagen: Die Größe und Richtung einer gleichförmiggeradlinigen Translation hat keinen absoluten Sinn, wohl aber die Aussage, daß sich ein Körper in geradlinig-gleichförmiger Translation befindet.

Darum ist es sinnvoll, wenn man sagt: die Erde dreht sich um ihre Achse, die Sonne aber steht still; und es ist nicht wahr, daß die Erde stillsteht und die Sonne die Erde umkreist.

Rein kinematisch, d. h. bewegungsmäßig, ist die Alternative sinnlos, weil die Bewegung ein Relativbegriff ist. Dynamisch, d. h. wenn man die auf- 
tretenden Kräfte, die Zentrifugalkräfte vor allem, beachtet, besteht die Alternative zu recht. Dies zeigt die Abplattung der Erde, die eine Folge der Zentrifugalkräfte ist, die der Erddrehung wegen auftreten. Die Erde wäre, so denkt man, auch abgeplattet, wenn sie ganz allein, ohne Sonne und Sterne, im Weltraume rotieren würde. Wogegen erfolgt aber dann ihre Drehung?

Diese Frage hat Newton dadurch beantwortet, daß er einen absoluten Raum und eine absolute Zeit postulierte: die Rotation erfolgt in der absoluten Zeit gegen den absoluten Raum. Dies ist freilich keine Antwort, welche das Paradox löst, sondern eine petitio principii. Man muß aber zugeben, daß Newtons Lösungsversuch für seine theoretisch-physikalischen Zwecke genügend war: Gesteht man zu, daß die absolute Zeit und der absolute Raum sinnvolle Begriffe seien, so weiß man, was die Beschleunigung sein soll - nämlich die Änderung der Geschwindigkeit, bezogen auf diese absoluten Größen - und dies ist für den Aufbau der Mechanik das wesentliche.

Newton hat aber seine Lösung des Problems auch aus philosophischen oder theologischen Gründen für höchst befriedigend gehalten, wie aus dem berühmten Scholium generale hervorgeht, das er der zweiten Auflage der Principia von 1713 angefügt hat.

Das Scholium beginnt mit einem Hinweis auf die Schwierigkeiten, die der cartesischen Wirbelhypothese entgegenstehen: diese kann das Verhältnis der Umlaufzeiten der Planeten nicht richtig erklären und noch viel weniger die stark exzentrischen Bahnen der Kometen, die ja den gleichen Gesetzen wie die Planetenbahnen genügen.

Hierauf folgt eine Beschreibung des Planetensystems: Alle Planeten und Monde laufen im gleichen Umlaufssinn annähernd in einer Ebene, und diese Regelmäßigkeit folgt nicht aus den Gesetzen der Mechanik, wie denn auch die Kometen sich nach allen möglichen Richtungen hin bewegen. Sie stören aber das Planetensystem nur wenig, weil sie es schnell durcheilen und nachher in großer Entfernung sehr langsam weiterlaufen.

Diese hochelegante Anordnung des Sonnensystems kann daher nur durch den Ratschluß und die Herrschaft eines intelligenten und mächtigen Wesens entstanden sein. Und wenn die Fixsterne die Zentren ähnlicher Systeme sind, sind auch sie alle ähnlich gebaut und unterstehen dem Gebote eines Einzigen: zumal da das Fixstern- und das Sonnenlicht dieselbe Natur haben und alle Systeme sich gegenseitig Licht zustrahlen.

Dieser Eine, so wird nun gesagt, regiert all dies, nicht als Weltseele, sondern als Herr des Universums. Gott ist ewig, unendlich, allmächtig und 
allwissend, d. h. er dauert von Ewigkeit zu Ewigkeit, ist allüberall da, regiert alles und weiß alles, was geschieht oder was gewußt werden kann ${ }^{3}$.

Indem er immer dauert und überall da ist, erzeugt er (constituit) den Raum, die Ewigkeit und die Unendlichkeit. Wie auch der kleinste Raumteil immer da ist und jeder unteilbare Augenblick überall, so ist auch der Schöpfer und Herr aller Dinge nicht niemals und nirgends. In Ihm ist alles enthalten und bewegt sich alles ${ }^{4}$.

Von Gottes innerem Wesen wissen wir freilich gar nichts. Wir erkennen ihn nur durch seine Eigenschaften und Attribute, durch den wunderbaren, weisen Bau der Dinge und durch die Endursachen. Wir verehren ihn aber seiner Herrschaft wegen. Denn Gott ist ohne Herrschaft, Vorsehung und Endursachen nichts als das Fatum und die Natur.

Von ihm auf Grund der Erscheinungen zu handeln, gehört in die Experimentalphysik.

Man vergleiche nun diese Aussagen über Gottes Allgegenwart mit dem, was Newton über Raum und Zeit sagt, wo er sie als die «primären Örter aller Dinge» bezeichnet, und man wird wohl kaum daran zweifeln, daß auch durch jene Formulierungen ein tieferer Sinn angedeutet werden soll.

Nachdem Newton von Gott, Zeit und Raum gehandelt hat und die bemerkenswerte Erklärung gemacht hat, daß die Physik eine besondere Art der Theologie sei, fährt er fort:

${ }^{3}$ D. i. der Wortlaut der zweiten Auflage: «quae fiunt aut sciri possunt». Die späteren Auflagen haben: «quae fiunt aut fieri possunt», was ich für einen Druckfehler halte. Dieser konnte leicht entstehen, weil im Druck die beiden Worte ähnlich aussehen. Zudem ist «fiunt aut fieri» eine konventionelle Wendung.

${ }^{4}$ Hiezu werden folgende Bibelstellen angeführt: Paulus in Acta 17, 27, 28, Moses Deut. 4, $39 ; 10$, 14. Ps. $139,7,8$, Salomo 8, 27, Hiob 22, 12, Jeremia 23, 23, 24. Es handelt sich hier um Sätze wie die folgenden:

Acta $17,27 \ldots$ damit sie Gott suchten, ob sie ihn wohl spüren und finden möchten, da er doch nicht fern ist von einem jeden unter uns. Denn in ihm leben wir, bewegen wir uns und sind wir.

Deut. 10, 14. Dem Herrn, Deinem Gott, gehört der Himmel und aller Himmel und die Erde und alles, was drauf ist.

Ps. 139, 7, 8. Wohin soll ich gehen vor Deinem Geiste?

Wohin soll ich fliehen vor Deinem Angesicht?

Stiege ich hinauf in den Himmel, so bist Du dort;

Schlüge ich mein Lager in der Unterwelt auf - auch da bist Du.

Jerem. 23, 23, 24. Bin ich denn nur ein Gott aus der Nähe und nicht ein Gott aus der Ferne? Kann sich einer so heimlich verbergen, daß ich ihn nicht sehe? Erfülle ich nicht den Himmel und die Erde? spricht der Herr. 
In diesem Sinne habe ich die Erscheinungen des Himmels und unseres Meeres durch die Schwerkraft erklärt, habe aber für diese noch keinen Grund angegeben. Diese Kraft muß nämlich aus irgendeiner Ursache entspringen, die bis in die Mittelpunkte der Sonne und der Planeten dringt ohne Abnahme ihrer Fähigkeiten. Aus den Erscheinungen habe ich aber ihren Grund nicht herleiten können: et Hypothesis non fingo - ich erdichte keine Hypothesen.

Das Scholium schließt mit einigen Bemerkungen über einen höchst subtilen Spiritus, der alle Körper durchdringt und der, wie Newton vermutet, für die elektrischen Eigenschaften der Materie, für ihren Zusammenhalt, für die Optik und für die Nervenphysiologie von großer Bedeutung sein soll. Es liege aber kein genügendes Erfahrungsmaterial vor, um hier quantitative Gesetze aufstellen zu können.

Das Scholium macht, mit seiner Vermischung von physikalischen, naturphilosophischen und theologischen Betrachtungen, keinen einheitlichen Eindruck. Auch ist die in ihm zum Ausdruck gebrachte Theologie recht sonderbar. Besonders auffallend ist die Behauptung, daß die in den Principia gegebene Erklärung des Sonnensystems nichts anderes sei als die Lehre von Gott, insofern er sich in seinen Werken offenbart. Die Physik wird somit durchaus als natürliche Theologie verstanden.

Betrachtungen darüber, wie der Bau der Welt doch höchst wunderbar und zweckmäßig sei, machen am Ende eines durchaus nüchternen, mathematisch-physikalischen Lehrbuches auf den modernen Leser einen fremdartigen Eindruck.

Wir haben uns heute an die physikalischen Begriffe von Raum und Zeit und an die Gesetze der allgemeinen Gravitation derartig gewöhnt, daß uns der Gedanke, es werde die Erde von der Sonne, der Mond von der Erde angezogen, und daß Sonne und Mond die Gezeiten des Meeres mechanisch hervorbringen, völlig vertraut ist. So kommt uns das Wunderbare und Unbegreifliche daran kaum mehr zum Bewußtsein.

Die Newtonsche Auffassung dieser Dinge war aber damals, auch wenn wir nur ihren eigentlichen physikalischen Aspekt betrachten, ganz neuartig. Man empfand es noch, daß es sich hier um Anschauungen von großer philosophischer Tragweite handle, wie dies aus den Reaktionen von Newtons bedeutendsten Fachgenossen, Huygens und Leibniz, hervorgeht. Daher sah sich Newton genötigt, den philosophisch-theologischen Hintergrund seiner Physik, wenn auch nur in gedrängter Form, anzudeuten. 
Newtons Philosophie steht vor allem im Gegensatz zurCartesischen Denkweise und greift auf eine ältere Überlieferung zurück, die in der italienischen Renaissance ihren Ursprung hat. Dies hat E. CAssirere ${ }^{5}$ überzeugend nachgewiesen.

Die Denker, die diese Entwicklung trugen, sind für uns heutige von der Persönlichkeit Descartes' und von seinem mathematisch-philosophischen Denken überschattet. So wichtig aber Descartes für die Entwicklung der neueren Philosophie und Mathematik ist, so gering sind doch seine Verdienste um die Grundlegung der neuen Physik. Sein auf mathematische Klarheit zielender Geist hatte ein ungenügendes Verhältnis zur empirischen, und deshalb irrationalen Wirklichkeit. Darum eigneten sich seine Ideen schlecht, um auf ihrer Grundlage Physik zu treiben ${ }^{6}$.

Freilich, gerade ihrer Klarheit, d. h. ihrer naiven Anschaulichkeit halber, wirkten Descartes' physikalische Ideen vorerst höchst überzeugend. Es scheint, daß auch Newton selber sich erst von dem Einflusse der in seiner Jugend allmächtigen cartesischen Denkweise befreien mußte, wobei er auf älteres Gedankengut zurückgriff, das seiner Phantasie offenbar ermöglichte, sich in produktiver Art mit den Grundproblemen der damaligen Mechanik zu beschäftigen. Deswegen beginnt auch das Scholium generale folgerichtig mit polemischen Bemerkungen gegen Descartes.

Da die Quellen spärlich fließen, ist es freilich schwierig, die geistige Entwicklung Newtons zu verfolgen. Es gibt aber zwei umfangreiche Briefe ${ }^{7}$, die in den Jahren 1675 und 1679 geschrieben wurden, in denen er hauptsächlich Spekulationen, ein ätherisches Medium betreffend, auseinandergesetzt hat. Aus ihnen wird eine charakteristische Änderung in seinem Denken erkennbar.

Der Äther, von dem da die Rede ist, ist eben jener subtile Spiritus, der im Scholium generale erwähnt wird.

Im ersten Brief, der im Dezember 1675 an den Sekretär der Royal Society, Oldenburg, geschrieben wurde, wird u. a. gesagt, daß möglicherweise das ganze Naturgebäude nichts anderes sein könnte, als mannigfaltige Verbindungen gewisser ätherischer Spiritusse oder Dämpfe, die in einen dichteren Zustand kondensieren und hernach in mancherlei Form ge-

${ }^{5}$ Ernst Cassirer, Das Erkenntnisproblem in der Philosophie und Wissenschaft der neueren Zeit, 1. Band (2. Auflage, Berlin 1911).

${ }^{6}$ Einen guten Überblick über Descartes' physikalische Theorien bietet J.F. Scotт, The Scientific Work of René Descartes (London 1952).

7 Abgedruckt bei D. Brewster, op. cit. 
bracht werden. Dies geschah zuerst durch den direkten Eingriff des Schöpfers, hernach durch die Kraft der Natur, die so, gemäß dem Gebot «seid fruchtbar und mehret euch» ein vollendeter Nachahmer des Vorbildes wurde, das ihr der «Protoplast» gab.

Der Äther soll sich in beständiger Zirkulation befinden, wie dies dem Naturgeschehen überhaupt entspricht. Er strömt auf die Gestirne zu, wird in diesen kondensiert und verläßt sie wieder in der Form von Gasen oder Dämpfen. Dieser Prozeß soll erstens die Sonnenwärme erzeugen. Ferner erzeugt die Ätherströmung die Schwerkraft, die demgemäß der totalen Oberfläche der Körper proportional sein sollte.

Das ätherische Medium soll aber auch in den Nerven und im Gehirn eingeschlossen sein und durch seine Bewegungen, die dem Willen der Seele unterworfen sind, die Muskelkontraktion hervorrufen. Newton stellte sich dabei vor, daß der feine Äther, der doch gewöhnlich die Körper zu durchdringen vermag, in den Nerven und im Gehirn durch eine besondere Eigenschaft ihrer Häute - wir würden von einer «semipermeablen Wand» reden zurückgehalten werde. Dies wird durch physikalisch-chemische Betrachtungen über Mischbarkeit, Löslichkeit oder Legierbarkeit von Flüssigkeiten oder Metallen erläutert. Ähnliche Gründe könnten dazu führen, daß sich die Ätherwirbel der Sonne und der Planeten nicht mischen.

Wir sehen hier, daß Newtons damalige Spekulationen in vielem große Ähnlichkeit mit denen Descartes' besaßen. Insbesondere glaubte auch er, daß die Schwerkraft durch mechanisch-hydrodynamische Kräfte zustande komme, weshalb er an der Hypothese der Ätherwirbel Descartes' festhielt.

Obwohl er schon zehn Jahre früher erkannt hatte, daß die Schwerkraft der Sonne und der Planeten mit dem Quadrat der Entfernung abnimmt, war er doch noch weit von der Erkenntnis der allgemeinen Gravitation, d. h. von der Erkenntnis, daß jeder Massenteil jeden anderen gemäß dem Gravitationsgesetz anzieht, entfernt.

Der zweite Brief, im Februar 1679 geschrieben, ist an den berühmten Chemiker Roв. Boyle gerichtet, mit dem Newton befreundet war. Er handelt ebenfalls von der Ätherhypothese und von ihren Nutzen zur Erklärung physikalisch-chemischer und optischer Erscheinungen. Die Natur und die Wirkungsweise des Äthers werden jedoch wesentlich anders aufgefaßt als früher. Es soll sich jetzt um ein hochelastisches, sehr feines Gas handeln, das in die Körper zwar eindringt, dessen Dichte aber in den Körpern und in ihrer Umgebung geringer ist als im freien Raume: Je weiter man sich von 
den Körpern entfernt, desto dichter wird der Äther. Umgekehrt haben die Körper das Bestreben, aus Gegenden höherer Ätherdichte in diejenigen Gegenden zu gelangen, wo diese Dichte geringer ist. Mit Hilfe dieser Vorstellung, dachte Newton, könnte man auch die Schwerkraft erklären. Die Idee aber, daß sich in den Körpern Äther kondensiere, daß dieser Ströme und in solcher Weise Kräfte ausübe, wird ganz aufgegeben.

Der Äther wirkt nicht mehr mechanisch im Sinne Descartes'; denn bei diesem ist eine mechanische Wirkung zuletzt immer ein Zusammenstoß materieller Körper. Newtons Äther dagegen ist ein Träger elastischer Kräfte und ist seiner Natur nach als dynamisch gedacht. Seine Elastizität wird nicht, wie dies Descartes verlangt hätte, auf Bewegungen zurückgeführt und ist daher eine neue, besondere Eigenschaft. Somit wird hier das mechanistische Denken verlassen, wenn auch diese Wendung noch nicht mit vollem Bewußtsein geschieht.

Zu einer wirklich neuen Denkweise gelangte Newton erst, als er sich in den folgenden Jahren erneut mit den Grundlagen der Himmelsmechanik beschäftigte - das Resultat dieser Arbeit sind die Principia.

Aus der ersten Auflage, der das Scholium generale noch fehlt, ist allerdings der naturphilosophische Hintergrund nicht deutlich zu erkennen. Besonders wurden die Ansichten Newtons über die Schwerkraft schon von den Zeitgenossen mißverstanden, indem man schloß, er lehre die unmittelbare Fernwirkung materieller Körper aufeinander. Er aber bestritt dies lebhaft, da er sich über die Ursachen der Schwere überhaupt nicht geäußert, sondern nur ihr empirisches Vorhandensein festgestellt habe. Die Art und Weise, wie dies geschah, mußte aber notwendig zu den Folgerungen führen, die jedermann zog und die ihm doch gar nicht passen wollten.

Newton hatte sich bei $\operatorname{dem}$ Schluß, daß die Schwere eine bei allen Körpern auftretende Erscheinung sei, auf seine dritte «Regula Philosophandi» gestützt. Diese Regeln eröffnen das dritte Buch der Principia, das die Anwendung der vorher entwickelten physikalisch-mathematischen Sätze auf die Himmelsmechanik enthält.

Die dritte Regel lautet: Eigenschaften der Körper, die weder zu- noch abnehmen können und an denen alle Körper, mit denen man experimentieren kann, teilhaben, soll man für Eigenschaften aller Körper halten.

Hierauf folgt eine lange Erläuterung, in der schließlich festgestellt wird, daß auch die Schwere eine solche Eigenschaft sei, die sogar noch sicherer als die Undurchdringlichkeit der Körper nachgewiesen sei. Denn jene sei auch für Himmelskörper nachweisbar, diese aber nicht. 
Daraus schloß man, Newton rechne die Schwere, die in die Ferne wirkt, zu den wesentlichen Eigenschaften der Materie, ähnlich wie die Trägheit. Das war aber gar nicht seine Meinung. So schrieb er 1693 an den berühmten Philologen Bentley ${ }^{8}$ : «Es ist undenkbar, daß unbeseelte, stumpfe Materie ("inanimate, brute matter"), ohne Vermittlung von etwas anderem, das nicht materiell ist, auf andere Materie wirken könnte, ohne diese zu berühen. Aber das wäre so, wenn die Gravitation im Sinne der Epikuräer der Materie wesentlich und inhärent wäre. Das ist èin Grund, weshalb Sie mir die Vorstellung der eingeborenen Gravitation nicht zuschreiben sollten ... Die Schwere muß durch ein Agens verursacht sein, das dauernd nach gewissen Gesetzen wirkt. Ob aber dies Agens körperlich oder unkörperlich sei, das überlasse ich dem Urteil meiner Leser.»

Er hat ferner, um zu beweisen, daß er nicht an Fernkräfte glaube, in der lateinischen Ausgabe der Optik (1706) sowie in der zweiten englischen Auflage von $1717 \mathrm{im}$ Anhange, der die sogenannten «Fragen» enthält, jene alten Spekulationen, die er seinerzeit BoYLE mitteilte, abgedruckt, nach welchen ein im «Vakuum» ausgebreiteter Äther die Gravitation hervorrufen könnte. Ein Äther im Sinne der Cartesianer wird dagegen ausdrücklich verworfen:

«Wenn wir ein solches Medium verwerfen, so können wir uns auf die ältesten und berühmtesten Philosophen Griechenlands und Phöniziens berufen, die als Ausgangspunkt ihrer Philosophie ein Vakuum annehmen, ferner die Atome und ihre Schwere. Dabei schrieben sie die Schwere stillschweigend einer andern Ursache als der dichten Materie zu. Spätere Philosophen verbannen die Betrachtung solcher Gründe aus der Physik und ersinnen Hypothesen, die alles mechanisch erklären sollen, indem sie andere Gründe in die Metaphysik verweisen: Während doch die Hauptaufgabe der Physik darin besteht, von den Erscheinungen auszugehen, ohne Hypothesen zu erdichten, die Ursachen aus den Wirkungen zu erschließen, bis wir zum allerersten Grunde gelangen, der gewiß nicht mechanischer Art ist. Sie soll auch nicht nur den Mechanismus der Welt enthüllen, sondern vor allem Fragen der folgenden Art beantworten: Was befindet sich in den von Materie beinahe freien Räumen, und woher kommt es, daß sich die Sonne und die Planeten gegenseitig anziehen, ohne daß sich zwischen ihnen dichte Materie befindet? Wie kommt es, daß die Natur nichts umsonst tut, und was ist der Ursprung aller Ordnung und Schönheit,

${ }^{8}$ Newtoni Opera, by Horsley, IV. 438. 
die wir in der Welt sehen? Wozu dienen die Kometen?» usw. (28. «Frage» der Optik).

Gleichwohl hat er in der zweiten Auflage der Principia (1713), anders als in der Optik, nichts Näheres über die möglichen Ursachen der Schwerkraft geschrieben, sondern sich mit Andeutungen über einen subtilen Spiritus begnügt, die, so wie sie dastehen, nicht recht verständlich sind. Auch ist die dritte Forschungsregel mit dem alten Kommentar unverändert übernommen worden, obwohl man aus ihr wirklich schließen sollte, daß auch die Schwere zu den wesentlichen Eigenschaften der Materie gerechnet werden muß, was doch gar nicht Newtons Meinung war.

Alles in allem muß man darum zugestehen, daß es schwierig ist, sich aus dem, was Newton über Zeit, Raum und Schwere gesagt hat, ein klares Bild seiner Vorstellungen zu machen.

Aber die Ideen Newtons sind aus einer Überlieferung gespiesen, deren Quellen bedeutend reicher fließen. Indem wir uns diesen Quellen zuwenden, werden seine Ideen besser verständlich, und der innere $\mathrm{Zu}$ sammenhang der im Scholium generale angedeuteten Gedanken wird einigermaßen deutlich.

\section{Die Raumlehre der Italiener des 16. Jahrhunderts und ihre Quellen}

Der Ursprung der modernen Vorstellungen von Raum und Zeit liegt in Italien. Die Philosophen des 16. Jahrhunderts haben dort, in der Auseinandersetzung mit der umwälzenden Lehre des Kopernikus, die Vorstellungen geschaffen, die dann in den Händen Galileis und Newtons zur Grundlage unserer Physik werden sollten ${ }^{9}$.

Alle diese Denker betrachteten sich selber als Nachfolger Platos. Aber was man damals als Platonische Philosophie bewunderte, ist nicht nur das, was uns aus den Platonischen Dialogen anspricht. Es war auch nicht einfach der Neuplatonismus der späteren Antike. Zwar wurden die Dialoge Platos und die Enneaden Plotins fleißig gelesen und zitiert, aber all dies wurde in einer für uns fremdartigen Weise verstanden und gedeutet. Überdies treten ganz neue Motive auf, die dieses Denken grundsätzlich vom antiken Denken unterscheiden, und dazu gehören die Theorien vom Raume. Diese ha-

\footnotetext{
${ }^{9}$ Vergleiche hiezu: Ernst Cassirer, Das Erkenntnisproblem. Diesem Werke verdanke ich entscheidende Anregungen.
} 
ben wenig Ähnlichkeit mit dem, was Plato im Timaios über den Raum gelehrt hat ${ }^{10}$, ja sie widersprachen ihm geradezu.

Plato reiht den Raum in die drei «Gattungen» ein, die schon bestanden, bevor die Welt wurde. Diese sind:

1. Etwas Unveränderliches, das in nichts übergeht noch etwas aufnimmt und das nur dem Denken zugänglich ist: d. i. das Reich der Ideen.

2. Etwas dem ersten Ähnliches, das nach ihm benannt wird. Dieses ist ewig wechselnd, und dem Meinen und den Sinnen zugänglich: das ist die Erscheinungswelt.

3. Der Raum, in dem alles wird, eine schwer zu begreifende, dunkle Gattung. Er nimmt alles Werdende auf und ist gleichsam seine Amme. Ein gestaltloser Schoß, der alles umschließt, hat er in einer zweideutigen und kaum erklärlichen Art teil an der göttlichen und ideellen Natur. Wir werden seiner auf eine dunkle, kaum begreifliche Art gewahr. Aber, indem wir unseren Geist auf ihn richten, träumen wir gleichsam und glauben, alles müsse einen Ort haben und einen Raum einnehmen: und was weder auf der Erde noch im Himmel sei, existiere überhaupt nicht.

Der Raum ist gleichzeitig eine Art ideeller Urmaterie, in die sich die Ideen einprägen. Dementsprechend dachte sich Plato die Elemente aus geometrischen Figuren, aus Dreiecken, gebildet.

Die Zeit aber faßte Plato als bewegtes Bild der Ewigkeit auf, das, anders als der Raum, zusammen mit der Welt entstand und durch den Lauf der Planeten gemessen wird.

Aristoteles, weniger abstrakt als Plato und auch naiver, faßte den Raum im wesentlichen als das auf, was einen Körper begrenzt ${ }^{11}$. Damit wird der Raum eigentlich zur Oberfläche. Die Zeit dagegen wird auf die Bewegung der Körper, vor allem der Himmelskörper, zurückgeführt.

Ähnlich sind die Vorstellungen Plotins, der hier mehr aristotelisch als platonisch empfindet (Enneaden VI. 3).

${ }^{10}$ Maßgebend für unsere Zwecke ist die lateinische Übersetzung Ficınos, die bis ins 18. Jahrhundert immer wieder gedruckt wurde. Auch Newton hat sie in seiner Bibliothek besessen. Über ihren Wert, siehe: J. FestugIÈre, La philosophie de l'amour de Marsile Ficin (Paris 1941), Appendice I. Hier sagt Festugière: «Certes, Ficin interprète Platon d'une façon qui n'est pas toujours orthodoxe: mes dans ses Commentaires seulement. Car je me suis rendu compte que sa traduction est en général exacte, qu'il suit avec fidélité la pensée du philosophe grec, bref, que les hommes du XVI ${ }^{\mathrm{e}}$ siècle, qui le plus souventn'atteignaient Platon que par Marcile Ficin, connaissaient bien l'original et non quelque moulage pour trop défectueux.»

${ }^{11}$ Physik, IV. Buch. 
Wenn nun die Italiener des 16. Jahrhunderts Platos Raumlehre nicht beachteten, die des Aristoteles sogar direkt verwarfen, so fanden sie freilich doch Anregungen in antiken Lehren, die aber ganz anderer Herkunft sind. Die ersten antiken Schriften, die Ficino 1471 herausgab, waren ja nicht diejenigen Platos, sondern die im Corpus Hermeticum vereinigten Gespräche oder Reden, die dem Hermes Trismegist us ${ }^{12}$ zugeschrieben wurden. Diesen Hermes betrachtete man als eine historische Persönlichkeit, die zur Zeit Moses in Ägypten gelebt haben sollte - manche hielten ihn gar für einen Zeitgenossen Abrahams. Wie Moses, oder vielleicht durch dessen Vermittlung, sollte er göttliche Offenbarung empfangen haben.

Ferner erhielt man gegen Ende des 15. Jahrhunderts Kenntnis von der jüdischen Geheimtradition, der Kabbala. Diese Lehren führte die jüdische Überlieferung auf die Offenbarungen zurück, die Moses auf dem Sinai zuteil wurden. Sie zeigen ein deutlich neuplatonisches Gepräge, was die Zuverlässigkeit der Überlieferung und den Offenbarungscharakter der Hermetischen Schriften zu bestätigen schien, denn diese sind auch neuplatonisch gefärbt.

Alle diese Weisheiten, so glaubte man weiter, hätten Pythagoras und Plato in Ägypten kennengelernt, und so sei die göttliche Offenbarung aufs neue aufgelebt. Die Erkenntnis, daß das Corpus Hermeticum erst aus dem zweiten oder dritten nachchristlichen Jahrhundert stammt, daß die Kabbala gar noch viel jüngeren Datums ist, hat sich erst im Laufe des 17. Jahrhunderts oder noch später durchgesetzt. Noch Boyle und Newton teilen die alte Meinung, daß alle Weisheit auf die mosaischen Zeiten zurückgehe, so auch die antike Atomtheorie, und daß diese Lehren teils durch die Vermittlung der Phönizier, teils durch Pythagoras und Plato den Griechen bekanntgeworden seien ${ }^{13}$. Dafür glaubte man auch in antiken Quellen eine Bestätigung zu finden. Im Corpus Hermeticum handelt nun die zweite Rede Hermes' an Asclepius, die in den alten Ausgaben die Überschrift $\lambda o ́ \gamma o \varsigma$

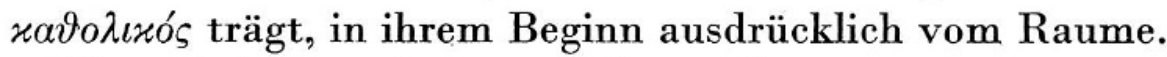

Hier wird folgendes ausgeführt: Alles, was sich bewegt, bewegt sich in etwas und durch etwas. Die Natur dessen, in dem sich etwas bewegt, ist der

${ }^{12}$ W.Scott, Hermes Trismegistus (Oxford 1924). - A.D. Nock et A. J. Festugière, Corpus Hermeticium (Paris 1945).

${ }^{13}$ Das ist der Sinn des Hinweises auf die Phönizier in der oben zitierten Stelle in NEwTons Optik. Siehe ferner: R. Boyle, The Sceptical Chymist, S. 71 (Everyman's Library). J.Tulloch, Rational Theology and Christian Philosophy in England in the $17^{\text {th }}$ Century, Vol. II, S. 303 (2. Auflage, 1874). 
Natur des Bewegten entgegengesetzt. Der bewegte Kosmos ist ein Körper. Daher ist der Raum unkörperlich. Was aber unkörperlich ist, gehört entweder Gott zu oder es ist Gott selber. Dieses unkörperliche Etwas, das Gott zugehört, muß seiner Natur nach ewige Substanz sein. Der Raum ist nun nicht Gott selber, denn er ist ein Objekt unseres Denkens, während Gott nur Objekt seines eigenen Denkens ist.

Daher ist der Raum die Wirksamkeit einer Kraft, die die Dinge umfängt. Er ist aber nicht das Leere, denn dies wäre Nichts. Also ist er, in dem sich alles bewegt, ganz Geist.

Gott selber ist nicht Geist und Wahrheit, aber er ist der Grund, durch den sie sind. Denn alles was ist, ist durch ihn.

Eine weitere Stelle, die diesen Gedankengängen entspricht, findet sich in dem Hymnus, der das 5. Buch beschließt: «Wohin soll ich blicken, wenn ich Dich preise? Aufwärts oder abwärts, nach innen oder nach außen? Denn Du bist der Ort, in dem alle Dinge enthalten sind, neben Dir ist kein Ort. Alle Dinge sind in Dir.»

Der Raum, von dem die zweite Rede handelt, ist natürlich nicht in erster Linie der Raum im gewöhnlichen Sinne, sondern der himmlische, außerkosmische Raum, in dem sich die kugelförmigen Himmelssphären drehen. Dagegen hat man bei den Worten des angeführten Hymnus wohl an den Weltraum schlechthin zu denken.

Man kann nicht daran zweifeln, daß sich in diesen Stellen jüdischer Einfluß bemerkbar macht. Die Worte des Hymnus klingen an die Verse des 139. Psalms (5-9) an, den Newton zitiert:

«Du hältst mich hinten und vorne umschlossen,

Du hast Deine Hand auf mich gelegt.

$\mathrm{Zu}$ wunderbar ist es für mich und unbegreiflich, zu hoch, als daß ich es faßte.

Wohin soll ich gehen vor Deinem Geiste?

Wohin soll ich fliehen vor Deinem Angesicht?

Stiege ich hinauf in den Himmel, so bist Du dort;

Schlüge ich mein Lager in der Unterwelt auf - auch da bist Du.»

Auch hier wird Gott als der Allgegenwärtige gepriesen, der den Menschen rings umschließt.

Die Deutung Gottes als «Ort» oder «Raum» (Makom, тó jüdische Tradition zurück. 
Die jüdischen Gottesnamen sind, wie man weiß, dadurch entstanden, daß man den Namen Gottes nicht mißbrauchen durfte (ganz abgesehen davon, daß alle Götter, ihrer vieldeutigen, übergroßen Macht halber, auch viele Namen tragen).

An Stelle des wirklichen Gottesnamen Jahwe verwendete man daher, wenn man über Gott schrieb, den Namen «ha-schamajim», d. h. der Himmel. So wurde «Himmel» zum Gottesnamen, den man nun aber ebenfalls nicht mißbrauchen durfte. Folglich wurde er durch «makom» ersetzt; denn der Himmel ist der Ort aller Orte. Dies geschah schon um $100 \mathrm{n}$. Chr. So wurde aber auch «Ort» zum Gottesnamen und damit höchst bedeutungsvoll. Darum entstanden schon in den ersten beiden nachchristlichen Jahrhunderten Spekulationen, die erklären sollten, warum Gott der «Ort» heiße und was der tiefere Sinn dieses Namens sei. Von den Rabbinen sind Sätze, wie die folgenden überliefert:

«Der Heilige, gelobt sei er, er ist der Ort der Welt, aber die Welt ist nicht sein Ort.»

«Gott durchdringt die Welt, er ist der Ort, der sie trägt, die Ausdehnung, die sie erhält.»

Solche Deutungen stützte man, wie dies noch Newton tut, durch Bibelstellen, z. B. durch Psalm 90, $1^{14}$.

Der spanische Rabbi Chasdai Crescas (1340-1420) hat bei seiner Kritik des Aristoteles auf diese Lehren zurückgegriffen ${ }^{15}$. Er behauptete, im Gegensatz zu diesem und zu Màmonides, die Möglichkeit des Vakuums und die Unendlichkeit des Raumes. Sein Hauptwerk Or Adonai (Gotteslicht) ist 1555 in Ferrara gedruckt worden, aber schon früher haben die italienischen Humanisten nachweislich von seinem Inhalt Kenntnis erhalten ${ }^{16}$.

In Italien hat zuerst Telesio (1508-1588), in bewußtem Gegensatz zu Aristoteles, die Selbständigkeit des Raumes und der Zeit gelehrt. Für uns werden aber vor allem die Lehren Francesco Patrizzis ${ }^{17}$ (1529-1593)

${ }^{14}$ Ich verdanke klärende Bemerkungen zu diesen Fragen Herrn Prof. A. BLoch in Basel. Siehe ferner R. Eisler, Weltenmantel und Himmelszelt, S. 470 (München 1910).

${ }^{15}$ Julius Guttmann, Die Philosophie des Judentums, S. $240 \mathrm{ff}$. (München 1933). - Harro A. Wolfson, Crescas' Critique of Aristotle, S. 201 (Cambridge Mass. 1929). - M. Joel, Don Chasdai Creskas' religionsphilosophische Lehren, S. 24 (Breslau 1866).

${ }^{16}$ M. JoEL, op. cit., S. 83.

${ }^{17}$ Eine Lebensbeschreibung Patrizzis, der in Dalmatien geboren und weit herumgetrieben wurde und in Rom starb, findet man bei Tн. A. Rixner und Tн. Siber, Leben und Lehrmeinungen berühmter Physiker, IV. Heft: Franciscus Patritius (Sulzbach 1823). Daselbst auch eine brauchbare Zusammenfassung seiner Philosophie. 
von Wichtigkeit, der auch Anregungen Telesios aufgriff und plastisch ausbaute.

Patrizzi verdankt man ferner eine der frühen Ausgaben der Hermetischen Schriften ${ }^{18}$, denen er auch eine lateinische Übersetzung beigegeben hat. In dieser Ausgabe ist der Anfang des 2. Buches (er setzt es an die 9. Stelle mit dem Titel Sermo Universalis), den wir oben angeführt haben, zum ersten Male enthalten ${ }^{19}$. Er fehlt nämlich in den alten Handschriften, und Patrizzi hat ihn mit Hilfe von Auszügen, die er bei Stobaeus fand, wiederhergestellt.

Es kann daher kaum bezweifelt werden, da $\beta$ seine Raumlehre entscheidend durch diejenige des «Hermes» bestimmt wurde. Seine eigene Philosophie findet man, zusammen mit den Hermetischen und anderen Schriften, in seiner Nova de Universis Philosophia ${ }^{20}$, die zuerst 1591 in Ferrara erschien.

Die Nova Philosophia zerfällt in vier Teile, mit den Titeln Panaugia, Panarchia, Panpsychia und Pancosmia. Sie beginnt wie folgt:

«Franciscus Patritius' Panaugia. Erstes Buch vom Lichte. Im 1583 Jahre des Heils, im 58. seines Autors.»

Franziskus Patrizzi wird nun eine neue, wahre und vollständige Philosophie der Universalien begründen. Er hat es gewagt, die folgenden, höchst wahren Grundsätze zu verkünden. Diese hat er, der Ordnung nach, durch göttliche Orakel, geometrische Notwendigkeiten, philosophische Vernunftsgründe und klarste Erfahrungen erläutert.

Vor dem Ersten, nichts.

Nach dem Ersten, alles.

Aus dem Anfang, alles.

Aus dem Einen, alles.

Vom Guten, alles.

Von Gott, dem dreieinigen, alles.

Gott, das Gute, das Eine, der Anfang, das Erste, sind dasselbe.

Aus dem Einen, die erste Einheit.

${ }^{18}$ Hermetis Trismegisti Libelli integri XX et Fragmenti eius discipuli Libelli III. Ferrara 1591.

${ }^{19}$ W. Scotr, op. cit.

${ }^{20}$ Mir lag die Ausgabe von 1593 vor, die den Titel trägt: Nova de Universis Philosophia Libris quinquaginta comprensa Autore Francisco Patritio, Philosopho eminentissimo et celeberissimo Romano Gymnasio summa cum laude eandem Philosophiam publice interpretante, quibus postremo sunt adiecata Zoroastris oracula CCCXX, ex Platonicis collecta, Hermetis Trismegisti libelli et fragmenta, etc. Venetijs, Excudebat Robertus Meiettus 1593. 
Aus der ersten Einheit, alle Einheiten.

Aus den Einheiten, die Essenzen.

Aus den Essenzen, die Leben.

Aus den Leben, die Engel ${ }^{21}$.

Aus den Engeln, die Seelen.

Aus den Seelen, die Naturen.

Aus den Naturen, die Qualitäten.

Aus den Qualitäten, die Formen.

Aus den Formen, die Körper.

All dieses ist im Raume.

All dieses ist in der Helligkeit ${ }^{21}$.

All dieses ist in der Wärme.

Dadurch wird die Rückkehr zu Gott bereitet.

Dieses ist Ziel und Zweck dieser unserer Philosophie, dessen sei versichert.

Um zu beweisen, daß diese, wohl noch in keinem Jahrhundert erhörten, von allem gewohnten abweichenden Axiome auf den sichersten Gründen ruhen, lasset uns also philosophieren:

Die Philosophie ist das Studium der Weisheit. Die Weisheit ist die Erkenntnis der Allgesamtheit. Die Allgesamtheit der Dinge beruht auf Ordnung. Die Ordnung beruht auf dem Früher und Später. Wer vom Späteren ausgehend zu philosophieren begänne, würde die Ordnung der Dinge verwirren, und über sie und sich Dunkelheiten ausbreiten. Von den ersten Dingen nehme daher unsere Philosophie ihren Anfang ${ }^{22} . »$

Die hier höchst feierlich vorgetragenen, ungewöhnlichen Axiome - et axiomata, et paradoxa, wie es im lateinischen Text heißt - sind eine $\mathrm{Zu}$ sammenfassung des ganzen Systems. Es handelt sich um eine Emanation der Dinge aus dem Einen, und, was für uns die Hauptsache ist: der ganze Prozeß findet im Raume statt (Haec omnia sunt in Spacio).

Von ihm handelt das erste Buch der Pancosmia unter dem Titel «de Spacio Physico» (Über den physikalischen Raum). Es beginnt wie folgt:

«Was war es aber, was der höchste Werkmeister (Opifex) vor allem anderen zuerst außer sich erschuf? Sollte und mußte nicht dasjenige zuerst geschaffen werden, dessen alles andere bedarf, damit es ist und ohne das es nicht sein kann, und das selber nichts anderes zu seiner Existenz bedarf? Dieses muß vor allem anderen notwendig da sein, und ist es gesetzt, so

${ }^{21}$ Siehe Noten ${ }^{57}$ und ${ }^{58}$.

${ }^{22}$ Um dem Leser einen Begriff von der Art des Patrizzischen Philosophierens zu geben, fügen wir im Anhang, neben dem lateinischen Text der hier und im folgenden aufgeführten Stellen, noch weitere Abschnitte hinzu. Besonders eindrucksvoll scheint es uns, wie Patrizzi das Licht, als die Freude, das Lachen der Welt, preist. 
kann auch alles andere gesetzt werden; nimmt man es aber weg, so wird auch alles andere aufgehoben. Dieses aber ist der Raum.

Alles, sei es körperlich oder unkörperlich, ist, wenn es nicht irgendwo ist, nirgends, und wenn es nirgends ist, ist es überhaupt nicht. Wenn es aber nicht ist, so ist es nichts. Was aber nichts ist, das ist nicht Seele, nicht Natur, nicht Qualität, nicht Form, noch ist es ein Körper.»

Sogar von der Universellen Gottheit gilt, daß, wenn sie allgegenwärtig ist, sie im Raume ist, und darum ist sie notwendig da. Dieser Raum, der allem vorangeht und auch außer der Welt ist, gehört nicht zu den Weltdingen. Er ist wirklich ein anderes Ding, das von der Welt verschieden ist.

Ferner sagt Patrizzi :

«Wenn das Substanz ist, was durch sich selber existiert, so ist der Raum am meisten von allem Substanz.»

Diese Aussage wird fünfmal variiert, und der Passus schließt mit den Worten:

«Der Raum existiert also ganz in sich und durch sich, er besteht daher immer durch sich und in sich; und er bewegt sich niemals, noch ändert er Wesen oder Ort, weder teilweise noch im ganzen.»

Hier tritt uns die Idee des «absoluten Raumes», klar erfaßt, zum erstenmal entgegen. Und hier begegnen wir den gleichen Argumenten, die uns später wieder begegnen werden, um die Wahrheit dieser Idee zu begründen: Was nirgends ist, das existiert überhaupt nicht. Also hat alles, was existiert, einen Ort und ist daher im Raume - und dies gilt auch von den unkörperlichen Dingen, ja auch von Gott. In genau demselben Sinne sagt noch NEwton, hundert Jahre später: «Sicher ist der Schöpfer aller Dinge nicht niemals und nirgends.»*

Patrizzi lehrt weiter, daß dieser ursprüngliche unendliche Raum, der als erster aus dem väterlichen Abgrunde hervorging, der somit sozusagen der Erstgeborene Gottes ist, vom ursprünglichen Licht ganz erfüllt wurde. Bevor ihn das Licht erfüllte, war er freilich nicht dunkel, denn die Finsternis stammt vom Undurchsichtigen, und das war nicht im leeren Raume.

Hernach aber wird er noch von der Wärme und der ursprünglichen Flüssigkeit, dem Äther, erfüllt.

In diesem flüssigen Äther bewegen sich die Gestirne, frei, durch lebendigen Antrieb, «wie Vögel in der Luft, wie Fische im Meer» ${ }^{23}$.

* All dies steht in direktem Gegensatz zu Platos Lehre, daß es ein Traum sei, wenn wir glauben, alles habe einen Ort und sei im Raume.

${ }^{23}$ Pancosmia, 13. Buch. 
Patrizzi konnte sich nicht entschließen, das kopernikanische, heliozentrische System ganz zu übernehmen, obwohl dieses sichtlich nicht schlecht zu seinen Lichtphantasien passen würde.

Dies kann allerdings durch Rücksichten auf die kirchliche Zensur bedingt sein, denn sein Buch wurde ihr natürlich vor dem Drucke unterworfen. Der Zensor, P. F. JACOB DE Lugo, hat, ohne freilich in den Text einzugreifen, verschiedentlich seine eigenen kritisch-warnenden Anmerkungen eingefügt, die mitabgedruckt sind. Gleichwohl ist das Werk 1595 auf den Index gesetzt worden.

Sei es der Zensur halber, sei es, weil er wirklich so dachte: Patrizzi stellt zwar die Autorität des Kopernikus sehr hoch, aber er gibt nur zu, daß sich die Erde um ihre Achse drehe, nicht aber, daß sie sich um die Sonne bewegte. Denn daß sich der Fixsternhimmel drehen sollte, scheint ihm, der gewaltigen Geschwindigkeit wegen, die er dann haben müßte, unwahrscheinlich. Dem Kopernikus aber wirft er vor, er habe behauptet, die Erde bewege sich auf einer Mondbahn. Auf diesen Unsinn sei er geraten, weil er glaubte, die Planeten und die anderen Gestirne würden auf Kreisen bewegt, an die sie angeheftet seien. Dies sei eine ganz schlechte Vorstellung, die Kopernikus in die Astronomie und in die Physik eingeführt habe.

Im Gegensatz hiezu vertrat Patrizzi die Ansicht, daß sich die Gestirne frei und beseelt «wie Vögel in der Luft» bewegen können. Die Erde dagegen, so sagt er wenigstens, dreht sich, mit ruhendem Zentrum im Mittelpunkt der Welt.

Sein unendlicher, lichterfüllter Raum, der nicht zu den Weltdingen gehört, ist darum nicht ganz dasselbe wie der absolute Raum Newtons; denn er ist in erster Linie der Feuerhimmel außerhalb der Fixsternsphäre, an deren Existenz Patrizzi, wie auch Kopernikus, allem Anschein nach noch glaubte.

Erst bei Giondano Bruno (1548-1600), der die geozentrische Vorstellung ganz aufgab und der für seine Überzeugung den Feuertod starb, wird der unendliche Raum zum physikalischen Raume in unserem Sinne. Er enthält unsere und unendlich viele anderen Welten. Jeder Stern ist bewohnt und beseelt, ein großes Lebewesen, das sich seines Ursprungs und Zieles bewußt ist. Und alle zeigen an und predigen im unendlichen Raume die unendliche Güte und Majestät des ersten Urhebers ${ }^{24}$.

${ }^{24}$ Giondano Bruno, Gesammelte Werke, Band 3: Vom unendlichen All und den Welten, deutsch von L. KuhlenBeck (Jena 1904). Diese fünf Dialoge wurden 1584 in England geschrieben. 
Er sagt ausdrücklich, es gebe keinen Grund und es habe keinen Sinn, an ein unendliches, unteilbares, einfachstes und vollkommenes Wesen zu glauben, ohne zugleich zuzugeben, daß es auch ein unendliches körperliches und räumlich entwickeltes gebe.

Die Vorstellung der verschiedenen Himmelssphären hält er für albern.

«Einzig ist also der Himmel, der unermeßliche Raum, der universelle Schoß, der Allumfasser, die Ätherregion, innerhalb deren alles sich regt und bewegt. In ihm sind zahlreiche Sterne, Gestirne, Weltkugeln, Sonnen und Erden sichtbarlich wahrnehmbar, und müssen unzählige andere vernünftigerweise angenommen werden. Das unendliche und unermeßliche All ist das Zusammenhängende Ganze, das aus diesem Raume und den in ihm befindlichen Körpern resultiert» (Vom unendlichen All, 3. Dialog).

Genau so wie schon Patrizzi sagt auch Bruno, daß die Sterne sich wie Vögel in der Luft aus eigenem Antrieb bewegten und nicht an Kugelschalen angeheftet seien. Auch für ihn, wie später für Newton, ist der Raum der Allumfasser, in dem sich alles regt und bewegt, und wenn er nicht ausdrücklich die Bibel zitiert, so zeigt doch seine Wendung deutlich genug, wie nahe der Raum der Gottheit ist, in der wir leben, uns bewegen und sind.

Ihn erfüllte seine Lehre vom unendlichen Raum und den unendlichen vielen Welten mit neuem, nie gekanntem Hochgefühl. Er hatte das Firmament, das unsere Welt vom Himmel trennte, gesprengt, und so flossen ihm Kosmos und Empyräum in ein einziges, unendliches, von Gott belebtes Universum zusammen. Darum läßt er in seinen Dialogen den zu Filoteos Überzeugung bekehrten Albertino begeistert ausrufen ${ }^{25}$ :

«Überzeuge uns von der Lehre des unendlichen Weltalls! Zerstöre diese eingebildeten Gewölbe und Kugelflächen, die so und so viel Himmel und Elemente begrenzen sollen!... Zerschmettere mit den Salven deiner durchschlagenden Gründe die stählernen Mauern und Wölbungen des ersten Beweglichen (d. i. der Fixsternhimmel), an das die Menge glaubt!... Schenk uns die Lehre von der Universalität der irdischen Gesetze auf allen Welten und von der Gleichheit der kosmischen Stoffe! ... Öffne uns das Tor, durch welches wir hinausblicken können in die unermeßliche ununterschiedliche Sternenwelt! Zeig uns, daß die anderen Welten im Äthermeer schwimmen, wie diese. Erkläre uns, daß die Bewegungen aller aus inneren Seelenkräften hervorgehen, und lehre uns im Lichte solcher Anschauungen mit sicherem Schritt fortschreiten in der Wissenschaft und Erkenntnis der Natur!»

${ }^{25}$ Vom unendlichen All, Ende des 5. Dialogs. 
Welche Hoffnungsfreude spricht aus diesen Worten! Was hier in «heroischem Furor» prophezeit wird, hat als erster GALILEO GALILEI verwirklicht, der mit seinem Fernrohr in die Sternenwelt hinausblickte und die Planeten mit ihren Monden als kleine Welten im Äther schwimmen sah, der mit dem Fallgesetz eines jener universellen Gesetze auffand und mathematisch formulierte. Aber wie nüchtern wirken seine Dialoge, wenn wir sie mit denen Brunos vergleichen. Bei ihm treten die Spekulationen über das Wesen von Raum und Zeit, gegenüber dem Bemühen, die Naturgesetze zu enträtseln, ganz in den Hintergrund.

Die von den Vorgängern Galileis entwickelten metaphysischen Vorstellungen des Raumes werden dagegen im 17. Jahrhundert in England nochmals aufgegriffen und finden bei Newton ihre endgültige Formulierung.

\section{Henry More (1614-1687)}

Der Kreis philosophischer Denker, der Newton die Gedankenwelt der italienischen Renaissance-Philosophie vermittelt hat, sind die sogenannten «Cambridge Platonists» ${ }^{26}$, und unter ihnen ist ihm Henry More auch persönlich nahegestanden.

Seit wann ihre nähere Bekanntschaft datiert, ist unbekannt. More erwähnt Newton 1680 in einem Briefe zum ersten Male. Sehr viel früher werden sie kaum häufiger verkehrt haben, denn Newtons Name erscheint nie in der regen Korrespondenz, die More mit seiner platonischen Freundin, Lady Anne Conway, führte und die erst mit deren Tode (1679) endet.

Aber in späteren Jahren muß doch ein reger Gedankenaustausch stattgefunden haben, der vor allem gemeinsamen theologischen Interessen galt.

${ }^{26}$ Die klassische Darstellung der Schule von Cambridge hat geliefert: Joнn Tulloch, Rational Theology and Christian Philosophy in England in the 17th Century (2. Auflage, Edingburgh 1874). - Ferner: Ernst CAssirer, Die Platonische Renaissance in England und die Schule von Cambridge (Studien der Bibliothek Warburg, 1932). F.J.Powicke, The Cambridge Platonists (London 1926). - Über Henry More im besonderen: Eine Auswahl aus seinen Schriften nebst einer Bibliographie findet man bei Flora J. Machinnon, Philosophical Writings of Henry More. - Das philosophische Gedicht, Psychozoia, wurde, mit einer lesenswerten Einleitung versehen, neu herausgegeben durch Geoffry BouLLOUgh, Philosophical Poems of Henry More (Manchester 1931). - Mores Briefwechsel mit Lady Conway wurde, zusammen mit neuen biographischen Einzelheiten, zum ersten Male veröffentlicht durch Majorie Hope Nicolson, Conway Letters. The Correspondence of Anne, Vicountess Conway, Henry More and their Friends, 1642-1684 (London 1930). 
Dies wird dadurch bekräftigt, daß Newton in Mores Testament ${ }^{27}$ als erster unter jenen wenigen aufgezählt wird, denen zu freundlichem Andenken an den Verstorbenen ein Ring gegeben werden soll.

Über die Persönlichkeit Mores sagt JoHn Tulloch in seiner klassischen Monographie, die den Cambridger Platonikern gewidmet ist: «Unter denen, die zur Schule von Cambridge gezählt werden, ist More am typischsten; er ist der lebendigste und interessanteste. Am meisten platonisch unter allen diesen Platonikern, ist er heiterer, natürlicher und menschlich vollkommener als alle andern.»

Wir dürfen somit das Sinnen und Denken Mores als repräsentativ für eine ganze Schule ansehen.

Platonisch sind diese Denker im Sinne der Renaissance. Ernst Cassirer sagt von ihnen: «Für Cudworth und More wie für Marsilius Ficinus und Pigo von Mirandula bildete Platon nur ein Glied in jener goldenen Kette der göttlichen Offenbarung, die, gleich ihm, Moses und Zoroaster, Sokrates und Christus, Hermes Trismegistus und Plotin umschließt. Er ist für sie der Zeuge und der lebendige Beweis dafür, daß die wahre Philosophie und das echte Christentum sich an keiner Stelle widerstreiten.»

Aber Cudworth und More, sie lebten nicht im 15. oder 16. Jahrhundert, sondern sie sind Zeitgenossen von Descartes und Hobbes. Dem überwältigenden Eindruck der Cartesischen Ideen konnten sie sich darum nicht entziehen, und gerade More hat seine eigentümliche Theorie des Raumes in der Auseinandersetzung mit Descartes entwickelt.

More begann als Platoniker im Sinne Ficinos. Der Platonismus schien ihm, der streng calvinistisch erzogen war, geradezu als Erlösung. Von starker, natürlicher Religiosität, war es ihm schon als Jüngling unmöglich, sich mit der starren Prädestinationslehre des väterlichen Glaubens abzufinden, die doch der Güte und Gnade Gottes, der Freiheit und Verantwortlichkeit des Menschen widerspricht. Im Platonismus glaubten er und die ihm Gleichgesinnten eine Lehre zu erkennen, die sie nicht nur unmittelbar ansprach, sondern der überdies die Würde einer gültigen göttlichen Offenbarung zukam. - In dem philosophischen Gedichte Henry Mores, Psychozoia genannt, heißt es darum:

(1. Gesang 4) So if what's consonant to Plato's school

(Which well agrees with learned Pythagore

Egyptian Trismegist, and th'antique roll

${ }^{27}$ Abgedruckt in Conway Letters. 
of Chaldee withdom, all with time hath tore

But Plato and deep Plotin do restore)

Which ist my scope, I sing out lustily ${ }^{28}$.

Wir sehen hier, wie auch More in Plato und Plotin nur die Reformatoren der alten, wahren, schon durch den ägyptischen Hermes verkündeten Philosophie sieht.

Die Psychozoia ist ein umfangreiches Gedicht - es besteht aus drei Gesängen mit über viertausend Versen. Sie ist 1640 entstanden und wurde zusammen mit andern Dichtungen Mores unter dem Titel Psychodia Platonica or a Platonicall Song of the Soul 1642 gedruckt. Sie soll eine platonische Beschreibung des kosmischen Lebens bieten. Dabei wird das heliozentrische Weltsystem zugrunde gelegt, ja, es wird metaphysisch bewiesen: So wie Gott das Zentrum der geistigen Welt ist, so ist die Sonne dasjenige der Körperwelt. Gott ist die Quelle der Erleuchtung und der Kosmos ist das Abbild der göttlichen, idealen Welt.

Auch Kepler hat ähnlich empfunden, und dies verlieh seinem Glauben an das heliozentrische System religiöse Weihe.

Die Anschauungen Mores, wie sie in seinem Gedicht zum Ausdruck kommen, sind nun aber in wesentlichen Punkten verschieden von jenen Platons oder Plotins. Der heliozentrische Glaube will eben nicht recht in jene antike Vorstellungswelt passen.

Nach More besitzt Gott eine vollkommene Herrschaft über den alleinen Kosmos. Er baut auf und zerstört, wie es ihm beliebt.

Alle unsere Seelen sind freie Ausflüsse seines Wesens. Neben diesen Einzelseelen waltet in der Welt eine Weltseele, die er, bezeichnend genug «low Spirit of the Universe», den «niederen Weltgeist», nennt. Dieser Geist ist ein allgegenwärtiges Wesen, aber: «So wie Noahs Sintflut die Erde überall überflutete und überall Wasser war, aber nicht jeder Teil Wasser in jedem Teil der Erde, oder nicht alles Wasser in jedem Teil der Erde war;

${ }^{28}$ Es ist wahrscheinlich, daß More die Hermetischen Schriften in Patrizzis Ausgabe gelesen hat. Die 320 Orakel des Zoroaster, die im Titel der Nova de Universis Philosophia PATrizzIS genannt werden, hat dieser zuerst 1591 unter dem Titel: Zoroaster, et Eiusdam CCCXX oracula chaldaica, $e$ Tenebris eruta, et latine redita, in Ferrara herausgegeben. Diese werden wohl die in diesen Versen erwähnte Chaldäische Weisheit sein. Es darf hier erwähnt werden, daß die Bibliothek Musgrave, die vor allem die Bücher, die ehemals in Newtons Besitz waren, enthielt, in ihrem Katalog auch «Patricii, Zoroaster, Hermes Trismeg. Oracula 1593» anführt. Das ist die oben zitierte Ausgabe von Patrizzis Hauptwerk von 1593 (R. De Villamil, Newton, The Man, London o. J.). 
so ist auch der niedere Weltgeist nicht in Gänze in jedem Teil der Welt. Sonst könnten wir ja die Antipoden flüstern hören. Denn unser niederer Mensch ist Teil des niederen Weltgeistes». ${ }^{29}$

Es klingt zwar ähnlich, wenn Plotin sagt, daß wir miteinander Empfindungsgemeinschaft hätten, weil wir durch die Allseele verbunden seien. Auch ein leise gesprochenes Wort wirke manchmal in die Ferne, und vieles zeige, da $\beta$ alle Dinge eine Einheit bildeten, weil die Seele eine sei ${ }^{30}$. Aber Plotin redet nicht von einem «niederen Weltgeist», sondern von einer Allseele, an der alle Menschen teilhaben.

Bei More sind dagegen die Einzelseelen ausdrücklich vom Weltgeist unterschiedene, freie Ausflüsse der Gottheit, und nur der «niedere Mensch», d. h. unsere unbewußte Natur, ist Teil des niederen Weltgeistes. Dieser ist gar keine eigentliche Seele, sondern er wird als wesentlich unbewußtes, dynamisches Agens aufgefaßt, das physiologische und physikalische Wirkungen vermittelt oder ausübt.

Nicht lange nach seiner Veröffentlichung lernte More die Schriften Descartes', den Discours de la Méthode, die Principia Philosophiae, kennen, die er mit wachsender Begeisterung las. Ihm imponierte die großartigphantasievolle Schau, zu der Descartes auf rationaler Grundlage gelangt war. So schrieb er ihm 1648 einen langen Brief ${ }^{31}$, in dem er ihm sagt, nur er könne ermessen, mit wie viel Lust sein Sinn durch die Lektüre seiner Schriften erfüllt worden sei. Freimütig gesteht er ihm: «Alle Meister der Naturgeheimnisse, die je waren oder auch sind, scheinen, mit deinem herrlichen Talent verglichen, bloße Zwerge und Däumlinge.»

Gleichwohl, und das ist offenbar der Zweck seines Schreibens, möchte er in aller Bescheidenheit seine Vorbehalte anbringen. Ihm schien nämlich die Lehre, daß Materie und Ausdehnung gleichwertige Begriffe seien, daß also alles Räumliche auch materiell sein müsse, unrichtig zu sein. Denn Gott, der doch allgegenwärtig ist, muß in gewisser Weise auch ausgedehnt, also räumlich oder im Raume sein. Ferner schreckte, wie er sagt, sein Zartgefühl vor dem Gedanken zurück, daß die Tiere keinerlei Empfindungsvermögen hätten. Er verstand zwar wohl, weshalb Descartes zur Ansicht kam, die Tiere seien bloß Maschinen : sie hätten nämlich, falls sie denken könnten, auch Teil an der unsterblichen Substanz, d. h. sie hätten eine unsterbliche Seele.

29 More, Einleitung zur Psychozoia.

30 Plotin, IV. 9. § 9. Deutsche Übertragung von R. Harder (Leipzig 1931/37).

31 Euvres de Descartes, par Adam et Tannery, Correspondance V (Paris 1903). 
Wie More in einem zweiten Brief (März 1649) schreibt, möchte er sich die Seelen, die Leben der Welt, wie sie Ficino nennt, als eine Art Sand oder Staub denken: aus dieser Vorratskammer strömen unendliche Seelenscharen in schicksalhaftem Triebe dauernd in die ihnen bereitete Materie über. Dergleichen sei freilich leichter gesagt als bewiesen.

In diesem Briefe sagt er auch, daß, wenn Gott die ganze Welt vernichten und viel später wieder eine neue schaffen würde, so hätte auch die Zeit zwischen den beiden Welten (intermundium illud seu absentia mundi) ihre Dauer, die man in Tagen, Jahren oder Jahrhunderten messen könnte. Ebenso habe auch das Nichts, d. h. das Vakuum, seine Größe, die man in Ellen oder Meilen messen könne.

Je länger je mehr schien es ihm übertrieben, daß alles in der Körperwelt rein mechanisch vor sich gehen sollte. Seine Befürchtung war, die cartesische Philosophie werde schließlich in reinem Mechanismus, Materialismus und Atheismus enden. Denn in einer mechanisch erklärten Körperwelt haben Gott und Geist keine Stelle mehr und die Welt besteht auch ohne sie. So wurde ihm Descartes zum «Nullibisten», denn bei ihm ist Gott nirgendwo. Damit entwickelte er sich aus einem Bewunderer zu einem Gegner der cartesischen Philosophie.

Sein Anliegen wurde darum, die Wirksamkeit nicht materieller, geistiger Wesenheiten in der Natur nachzuweisen, und da ihm der Raum etwas wesentlich Nichtmaterielles war, dem dennoch unzweifelhafte Realität zukam, spielt bei ihm die Theorie des Raumes eine zentrale Rolle.

Seine neue philosophische Denkart kommt wohl am besten in den Divine Dialogues, concerning the Attributes of God and his Providence in the World zur Geltung, die 1668 in London unter dem Pseudonym Franciscus Palaeopolitanus erschienen sind. Diese Dialoge sind sicherlich sein lebendigstes Werk, und es gibt in ihnen Stücke, deren poetischer Reiz auch heute noch nicht verblaßt ist. Es kommt hier so ziemlich alles vor, was More und seine Freunde interessierte und das in ihren Gesprächen diskutiert wurde. Einen breiten Raum nimmt dabei die Diskussion des Sinnes und der Bedeutung der Apokalypse ein, ein Thema, das damals viele, so auch Newton, beschäftigte. Neben eigentlich theologischen Fragen werden z. B. auch die Sitten und Gebräuche fremder Völkerschaften behandelt, über die man aus den Berichten der Weltreisenden erfuhr und durch deren Kenntnis der geistige Horizont geweitet wurde.

Die Polemik gegen Descartes ist, besonders am Anfang der Gespräche, vorherrschend. Es soll bewiesen werden, daß erstens der Raum ein von der 
Materie verschiedenes, metaphysisches Sein besitzt und daß ferner die Naturvorgänge, ja selbst physikalische Erscheinungen, nicht restlos mechanisch erklärt werden können.

Um seine erste Behauptung zu beweisen, führt More insbesonders das folgende «Gedankenexperiment» $\mathrm{an}^{32}$.

Man denke sich einen durchsichtigen Zylinder, etwa aus Glas. In diesem sei vom Zentrum seiner Deckfläche zum Umfange seiner Basis eine rote Gerade gezogen. Dreht man nun den Zylinder um seine Achse, so beschreibt die Gerade einen Kegel, der, wenn die Drehung hinreichend rasch erfolgt, auch als räumliches Gebilde sichtbar wird.

Dieser Kegel ist etwas durchaus Wirkliches, Sichtbares. Aber er ist nicht in der Materie des Zylinders - in dieser gibt es ja nur die Gerade -, sondern im Raum. Also ist der Raum etwas Wirkliches und von der Materie Verschiedenes. Dieses Ergebnis faßt einer der Sprechenden, namens Philotheus, wie folgt zusammen: «So kommst du, ob du lebst oder nicht, zur Überzeugung: Es war, ist und wird immer eine unbewegliche Ausdehnung geben, die von der beweglichen Materie verschieden ist.»

Auch Hylobares, «ein junger, witziger Materialist, von guten Anlagen», ist durch dieses Argument so überzeugt, daß er sagt: «Wenn der Gedanke, Materie und Ausdehnung seien reziproke Begriffe, je in mir wieder aufflammen sollte, so werde ich jenen Kegel als Kerzenlöscher benützen, um ihn zu ersticken.» Ferner wird aber auch festgestellt, daß der Raum kein bloßes Phantasma, kein imaginäres Wesen sein könne, wie dies HовBEs behauptet hatte. Denn der Raum ist ausgedehnt und meßbar und: «Non entis nulla est Affectio.» Daraus schließt Hylobares, daß es eine ausgedehnte Substanz geben müsse, die, viel subtiler als jeder Körper, alle Materien durchdringt. Dieser Schluß findet den Beifall des Bathynous, der Henry More selber vertritt. Dieser meint, Hylobares sei jetzt auch nicht mehr weit vom richtigen Verständnis Gottes entfernt. Er selber habe immer gerne gedacht, diese so subtile Ausdehnung (d.h. der Raum), die kein Mensch sich wegdenken kann, sei eine schattenhafte, allgemeine und etwas verwirrte Wahrnehmung der göttlichen Größe (Divine Amplitude). Denn sie ist immer da, auch wenn alle Materie vernichtet würde, und keine Materie ist ohne sie denkbar. In ihr werden alle Dinge notwendig wahrgenommen, wie sie leben, sich bewegen und sind. Hierauf wird Psalm 90, 1, 2 zitiert: «Lord, thou hast been our dwelling-place in all generations» worauf Bathynous fortfährt:

${ }^{32}$ Div. Dialog. 1, 26. 
«Darum haben die Kabbalisten nicht umsonst Gott die Namen adonai (der Herr) und makom (der Ort, der Raum) beigelegt, der der unbewegte Beweger, das Gefäß und der Erhalter aller Dinge ist.»

Daraus folgt also, daß der Raum, das Vakuum, eine Ausdehnung ist, durchaus von der Materie verschieden, aus der mit größter Sicherheit auf die Existenz eines geistigen Wesens geschlossen werden muß. Diese Ausdehnung ist unbeweglich und nicht zerteilbar (indiscerpible). Ihr entspricht notwendig ein reales Wesen, das mit dem göttlichen Wesen zusammenfällt.

Es ist daher unmöglich zu denken, es gebe keinen Gott in der Welt. Denn würde man sich alles vernichtet denken, der Raum würde übrigbleiben, man mag wollen oder nicht. Was aber notwendige Existenz mit sich führt, gehört zum Wesen Gottes.

Vor der Erschaffung der Welt hatte Gott keinen Ort als sich selber, und er war der erste und einzige Ort oder Raum für sich und alle seine Geschöpfe.

Die Materie ist dagegen nicht durch ihre Ausdehnung charakterisiert, sondern durch Teilbarkeit oder Zerteiltheit, durch gegenseitige Undurchdringlichkeit und durch wesentliche Inaktivität ${ }^{33}$.

Sie besteht aus passiven physikalischen Monaden, so klein, daß sie ohne Widerspruch nicht kleiner sein könnten und die nicht von selber zusammenhalten (Matter has no Vinculum of its own).

Der Zusammenhalt und die Aktivität der Materie hat ihren Ursprung in geistigen, spirituellen Prinzipien, die den Raum erfüllen und in ihm wirksam sind. Das sind die Geister, und diese sind im Raum und räumlich ausgedehnt, sonst wären sie ja nirgends.

Die Geister sind insofern der Materie entgegengesetzt, als sie unzerteilbar sind, d. h. eine wesentliche Einheit bilden. Ferner können sie sich gegenseitig durchdringen ${ }^{34}$, und schließlich sind sie nicht passiv, wie die Materie, sondern wesentlich aktiv. Bewußtsein oder Empfindungsvermögen besitzen sie dagegen keineswegs immer. Immer aber sind sie räumlich ausgedehnt, wobei sie ihre Ausdehnung durch Kontraktion und Dilatation verändern können.

Die unbewußten Geister Mores erinnern uns an die Kraftfelder, die zweihundert Jahre später durch Faraday in die Physik eingeführt worden sind. Diese sind ebenso stetig im Raume ausgebreitet. Sie superponieren sich, d. h. durchdringen sich, ohne sich gegenseitig zu stören, ${ }^{33}$ Div. Dialog. 1, 29.

${ }^{34}$ Diese Vorstellung findet sich auch bei Patrizzi, Panarchias Lib. XX. 
und sie werden für den Zusammenhalt der atomistisch gedachten Materie verantwortlich gemacht. So gesehen muß man sagen, daß Mores Geistertheorie, der er übrigens ein eigenes Werk gewidmet hat ${ }^{35}$, kein wirkliches Gegengewicht zum cartesischen Materialismus liefern kann.

More freilich sah in ihnen Träger einer Art Lebenskraft und betonte darum, die Grundkräfte der Welt seien nicht mechanisch, sondern spermatisch oder vital, und das sei der cartesischen Philosophie gänzlich entgegengesetzt.

Descartes hat sich bekanntlich vorgestellt, daß die Materie aus kleinen Teilchen bestehe, die den Raum völlig ausfüllen oder, streng genommen, die den Raum aufspannen oder bilden. Denn Raum und Materie sind dasselbe. Das Geschehen in der materiellen Welt besteht in der Bewegung der Teilchen. Die größeren bewegen sich durch die fein verteilte Materie hindurch, oder sie werden, wie die Planeten, von der Strömung der alles erfüllenden Materie mitgeführt. Stoßen zwei solche Teilchen zusammen, so prallen sie voneinander $\mathrm{ab}$, da sie undurchdringlich und vollkommen hart sind. Diese Zusammenstöße sind die Grundlage aller physikalischen Prozesse, und das ist der Sinn der Aussage, alle materiellen Vorgänge seien mechanischer Art.

Dynamische Begriffsbildungen im Sinne Galileis, oder gar ein Kraftbegriff, wie ihn Newton besaß, sind dieser Vorstellungswelt fremd. Descartes kannte zwar die Schriften Galileis, aber er hat sie nicht verstanden und abgelehnt. Es ist ihm darum aber auch nicht gelungen, die richtigen Stoßgesetze aufzufinden, die doch in seiner Theorie grundlegende Bedeutung haben. Demgegenüber betont Henry More, daß die Materie allein keine Quelle irgendeiner Veränderung sein könne. Das Geschehen werde vielmehr durch ein geistiges Prinzip, durch den Naturgeist oder die niedere Weltseele vermittelt und regiert.

In diesem Sinne sagt er $^{36}$ : «Wenn die vitalen Naturgesetze, die zum Wohle der Welt führen, nicht der Materie entspringen, dann muß es einen Naturgeist geben, der der Beweger und Regler der Materie ist. Er braucht keine Häckchen und Klammern um das zusammenzuhalten, was zusammenhalten soll, noch eine Schere, um zu trennen, was nach den Gesetzen der Natur getrennt werden muß.

$\mathrm{Da}$ ß ein Geist zu solchem fähig sei, das geben die gelehrten Herren zu, denn sie nehmen an, Seele und Körper seien vereinigt. Aber ich wundere ${ }^{35}$ The True Notion of a Spirit, F.J.Machinnon, op. cit.

${ }^{36}$ Remarks upon two Late Ingenious Discursions, S. 147, London 1676. 
mich, da wir doch aus diesen beiden Prinzipien bestehen, daß der Genius des Zeitalters so allgemein dahin geht, daß man die Richtlinien des Philosophierens nur von unserem körperlichen Teile hernimmt und nichts vom geistigen. Es scheint, man hat vergessen, daß wir auch geistiger Art sind, oder man verkennt die Fähigkeit des Geistigen durchaus und beträgt sich so, als ob man nichts sei als eine gewisse Menge philosophierender Materie.

Wenn nun gewisse Leute, gemäß der Roheit ihrer Begriffe, nicht glauben können, sie hätten eine Seele, wie würden sie doch aus ihren dumpfen Träumen aufgeweckt, wenn sie erkennen könnten, daß kein Stein ohne das Wirken eines Geistes zu Boden fällt oder daß nur durch ihn ein Holzstück im Wasser an die Oberfläche steigt. Wie ist es dann möglich, daß wir uns, entgegen dem Zwang des Naturgeistes, frei und spontan bewegen können, ja, daß wir himmlischer und göttlicher Regungen fähig sind, wenn nicht auch wir einen eigenen, selbständigen Geist besitzen?

Das sind Beweise für das Walten eines Naturgeistes, und das Wissen um sie ist zudem von höchstem Nutzen. Und darum schließe ich mit diesem alten, vertrauensvollen Lucrezischen Verse, der alte Platonische oder eher Pythagoräische Ansicht ausdrückt:

Ergo etiam atque etiam est in Mundo Spiritus ille Naturae, qui Materiam regit atque gubernat.»

In solchen beschwörenden Worten wird das Anliegen Mores ganz deutlich. Er möchte dem cartesischen Dualismus entgegenwirken, wo die Welt in eine Körper- und Geisterwelt auseinanderfällt. Er kämpft gegen den materialistischen Zeitgeist, wie er in der Philosophie Hobbes zum Ausdruck kommt. Ihm scheint, daß die Menschen mehr und mehr die Wirksamkeit seelischer Mächte unterschätzen, ja übersehen. Für ihn ist das Vorhandensein der Schwerkraft und der damit zusammenhängenden hydrostatischen Kräfte ein Beweis - man bemerke wohl, ein physikalischer Beweis - für die Wirksamkeit geistiger Agentien. Weitere Beweise waren ihm Geistererscheinungen und Hexerei, weshalb er Nachrichten hierüber fleißig gesammelt hat und immer wieder betonte, daß es durchaus unwissenschaftlich sei, derartige Dinge aus bloßem Vorurteil nicht ernst zu nehmen.

Die ganze, von wunderbaren Kräften erfüllte Welt ist im göttlichen Raume enthalten, ist also ein Reich Gottes. Unendlich ausgedehnt, aber doch meßbar, d. h. geometrisch wohl bestimmt, ist der Raum eine denknotwendige Wirklichkeit. Er ist gleichsam das allerrealste Wesen Anselms, dessen Existenz ontologisch bewiesen werden kann. Würden die Menschen 
diese Wahrheit einsehen, so müßten sie auch erkennen, daß der Physik, in der ja der Raum ein Grundbegriff ist, geistige, nicht materielle Prinzipien zugrunde gelegt werden müssen.

Die Ähnlichkeit gewisser Argumente Mores mit denen Patrizzis, insbesondere der Schluß, daß das, was nirgends ist, nicht existiert, und daß daher auch die unkörperlichen Wesen, die Geister, im Raume und räumlich ausgedehnt sein müssen, spricht dafür, daß er Patrizzis Philosophie gekannt hat. $\mathrm{Da} \beta$ er das Corpus Hermeticum gelesen hat, sagt er selber, und er zitiert es auch in seinen Noten zur Psychozoia. Schließlich weist er ausdrücklich auf die jüdische Tradition hin, wenn er zum Beweise seiner Lehre den Gottesnamen «makom» anführt und den 90. Psalm zitiert. Diese hat in seinem Denken überhaupt eine wichtige Rolle gespielt, und er galt darum auf diesem Gebiete als Kenner. Seine Kenntnisse schöpfte er aus besten Quellen.

Der Herausgeber der Kabbala Denudata, Knorr von Rosenroth ${ }^{37}$ hat sich, da dies offenbar bekannt war, an ihn gewendet ${ }^{38}$, und ihn um Mitarbeit gebeten.

Im Februar 1672 schickte er ihm kabbalistische Manuskripte, die More sogleich einem Kreise von Fachleuten vorlegte. In einem seiner Briefe an Lady Conway lesen wir ${ }^{39}$ :

«Zum Nachtessen hatte ich am letzten Sonntag unseren Professor der Orientalischen Sprachen ${ }^{40}$, und einen anderen Theologen, der ein Kenner der Rabbinen; ferner den Sohn eines schwedischen Bischofs, der wohl er-

37 Conway Letters, S. 324.

${ }^{38}$ Christian Knorr von Rosenroth, lebte 1636-1689 und ist heute noch als Dichter des schönen Kirchenliedes «Morgenglanz der Ewigkeit, Licht vom unerschaffnen Lichte» wohlbekannt. Weit gereist, lernte er wohl in Holland den berühmten MERcurius vaN Helmont (d. i. den Sohn des Paracelsisten Babtist v. H.) kennen. Mit ihm gab er einen Entwurf des Naturalphabets der hl. Sprache heraus. Ausgehend von der damals verbreiteten Vorstellung, das Hebräische sei die Ursprache und damit auch die natürliche Sprache, sollte dieses Naturalphabet die Grundlage für den Unterricht taubstummer Kinder abgeben. Von Helmont vermittelte die Beziehung Knorrs zu More. Seine Bemühungen um die Kabbala sollten letzten Endes der Bekehrung der Juden zum Christentum dienen. In späteren Jahren war er, obwohl Protestant, Hofrat des katholischen Pfalzgrafen in Sulzbach. Als Gelehrter der damaligen Zeit beschäftigte auch ihn die Auslegung der Apokalypse. Als Alchimist gehörte er der «philosophischen» Richtung Fuudos an.

${ }^{39}$ Conway Letters, S. 350.

${ }^{40}$ Dies ist wohl Cubworth. Dieser war ein Kenner des Judentums und darum Mitglied der Expertenkommission, die Cromwell zu beraten hatte, als er 1655 den Juden den Aufenthalt in England wieder gestattete (Powrcke, op. cit). 
fahren ist in dieser Wissenschaft, und einen Juden. Nach dem Essen ergriff ich die Gelegenheit und las ihnen Auszüge aus Peganius' (d. i. Knorrs) Brief vor. Alle billigten sehr seinen Plan. Was den IsaAc Luria (1534-72) anbetrifft, dessen Kommentar in M.S.S. dem Peganius helfen soll, den Zoar zu verstehen, so sagte mir der Jude, daß sie diesen Isaac Luria für den besten Kenner der Kabbala in der jüdischen Nation hielten.»

Man sieht hieraus, daß sich More nicht nur aus Büchern, sondern auch durch direkten Verkehr mit jüdischen Gelehrten belehren ließ.

Eigentlich kabbalistische Schriften hat er freilich wohl erst durch KNORRS Vermittlung kennengelernt, und er fand sie zuerst wenig anziehend. Genaueres Studium ließ ihn aber dann doch glauben, «daß köstliches Gold in diesem kabbalistischen Plunder enthalten sei, das dem forschenden Auge nicht verborgen bleiben könne».

Nach seiner Ansicht gingen diese Lehren wirklich auf Offenbarungen zurück, die Moses auf dem Sinai erhalten hatte, doch seien diese im 1. Jahrhundert v. Chr. durch die Juden verdorben worden. Damit glaubte er manche Ungereimtheiten erklären zu können. Die noch unverdorbene Kabbala habe Pythagoras durch gelehrte Juden kennengelernt, weshalb er dessen Philosophie als gute Quelle betrachtete ${ }^{41}$.

Für die Kabbala Denudata verfaßte er zwei Abhandlungen, in denen, in einer Art Thesen, der Inhalt dieser Philosophie zusammengefaßt wird. Besonders merkwürdig ist hier die Schrift: Grundlagen einer Philosophie, die jede Schöpfung im eigentlichen Sinne leugnet ${ }^{42}$.

Hier findet man in sechzehn Thesen eine eigenartige Monadologie ${ }^{43}$, die in vielem sehr stark an Gedanken Leibniz' erinnert und diesen wohl auch angeregt hat. Am Schluß wird ein seltsamer Traum mitgeteilt, den More im April 1675 geträumt haben will und der den zweideutigen, halb göttlichen, halb teuflischen Charakter der Kabbala zum Ausdruck bringen soll.

Bei genauerem Zusehen wird man allerdings in den sechzehn Thesen auch manches finden, was sehr an Mores eigene Philosophie erinnert. Daraus folgt, daß sein Traum sinngemäß auch als Kritik dieser, seiner eigenen Philosophie aufgefaßt werden kann. Sie ist nämlich, wie wir schon sahen, nicht in der Lage, dem Abgleiten in den Materialismus wirksam entgegenzutreten.

${ }^{41}$ Brief Mores in Kabbala Denudata, 1. Band, 2. Teil, S. 173 (Sulzbach 1677).

42 Ebenda, S. 293.

${ }^{43}$ Die «Monaden» werden bei More im Sinne Giondano Brunos als kleinste Einheit verstanden, die kleiner nicht gedacht werden könnten. 


\section{Der Abstieg der Weltseele und der Aufstieg des Raumes}

Die Gedanken Mores über den Raum und die in ihm wirksamen Kräfte sind, wie man leicht feststellen kann, ganz ähnlich wie diejenigen Newtons. Wenn wir das, was dieser große Mann nur angedeutet hat, im Sinne von More interpretieren, so werden wir wohl nicht fern von seiner wirklichen Meinung sein.

In diesen Lehren gelangte eine Entwicklung, die in der italienischen Renaissance anhob, zu ihrem Abschluß. Sie führte zu einer Weltanschauung, die von der neuplatonischen Schau, die der Ausgangspunkt gewesen, gänzlich verschieden ist.

In neuplatonischer Sicht könnte höchstens das Empyräum, die außerkosmische Ätherregion, als unendlicher, unbeweglicher, göttlicher Raum gelten. In jenen Gegenden sind die ewig seienden Ideen beheimatet, während die Welt nur ein unvollkommenes, dem Wechsel unterworfenes Abbild des Ewigen ist. Die irdische Welt aber, sie ist gar ein Reich des Zufalls, und was in ihr geschieht, ist ohne tiefere Bedeutung für die wahre Erkenntnis - hier gilt ein bloßes «Meinen».

In der Welt regiert zwar die Weltseele, die allem Einheit und Leben verleiht. Aber dies ist nur möglich, weil diese ein Teil jener außerkosmischen, ewigen Welt ist. Dort ist ihre wahre Heimat, und all ihr Wissen stammt von dort. Dorthin geht auch ihre Sehnsucht, denn ihr irdisches Dasein ist gleichsam eine Verbannung.

Wenn jetzt More und Newton den physikalischen Raum als ewig und unveränderlich, wenn sie ihn als Ausdruck der göttlichen Größe und Allgegenwart auffassen, so übernimmt er damit das Erbe des Empyräums. Denn für dieses ist im heliozentrischen Weltsystem kein Raum mehr da.

Raum und Zeit werden jetzt die Örter aller Dinge; in ihnen ist alles Seiende notwendig enthalten. Was in Raum und Zeit sich abspielt, ist kein Spiel blinden Zufalls, sondern der Ausdruck der Naturgesetze, die Gott selber angeordnet hat.

In der Erfahrungswelt offenbart sich darum Gottes gesetzgeberischer Wille, und dies verleiht ihr höchsten Wert. Das irdische Geschehen ist kein unvollkommenes Abbild einer ewig seienden Ideenwelt, sondern im Fluß der Erscheinungen erkennen wir das Walten von Gesetzen, die, obwohl rätselhaft, dennoch von uns erforscht werden können. Das Naturgesetz übernimmt damit die Rolle der platonischen Idee und es verwirklicht sich in der raum-zeitlichen Erfahrungswelt. 
Wir sehen also, daß der Raum und die Zeit in der Rangordnung der Dinge an höchste Stelle hinaufgerückt sind. Während sie vergeistigt werden, sinkt die Weltseele hinunter und wird zum «niederen Weltgeist», einem unbewußten, physikalischen Agens, zu einer Art Kraftfeld. Der Weltgeist steht allerdings höher als die Materie, weil er aktiv ist und jede Tätigkeit vermittelt. Durch ihn werden die Naturgesetze verwirklicht.

Diese geistige Substanz erfüllt auch bei Newton überall den Weltenraum; darauf zielt seine Frage: «Was befindet sich in den von Materie beinahe freien Räumen ?», denn diese hat er sich offenbar nicht völlig leer gedacht. Aber sein subtiler Spiritus, der allen Raum erfüllt, ist keine eigentlich geistige Substanz, sicher keine Seele mehr. Denn seine Funktionen sind alle durchaus körperlich, d. h. physikalisch, chemisch oder physiologisch. Nun hat allerdings Newton, wie More, die Materie, als etwas Grobes, Unbeseeltes und Passives, dem aktiven und daher geistigen Äther gegenübergestellt. Er rechnete die Schwerkraft, d. h. die Tatsache, daß sich die Körper gegenseitig anziehen, nicht zu ihren wesentlichen Eigenschaften, die unmittelbare Wirkung in die Ferne lehnt er ab. Ebenso wollte er den Energiesatz nicht als ein allgemeines mechanisches Prinzip anerkennen. Seiner Ansicht nach bleibt die Energie nur erhalten durch die Wirkung besonderer, aktiver Kräfte, und wo diese fehlen, erlahmt die Bewegung der Materie. All dies ist eine recht gewaltsame Deutung der mechanischen Prinzipien, durch welche Geistiges auch dort nachgewiesen werden soll, wo es eigentlich nicht gefunden werden kann.

Newtons unmittelbare Nachfolger haben darum die Gravitation als Fernkraft aufgefaßt und sie mit zu den mechanischen Eigenschaften der Körper gerechnet. Wenn sie den Äther auch beibehielten, so hielt man ihn für einen besonderen, feinen Stoff, dem nichts Geistiges anhaftet. Auch Newtons theologische Raumtheorie wurde nicht beibehalten ${ }^{44}$.

Geblieben aber ist die Idee, daß der Raum, der alle Dinge enthält, eine eigene, von der Materie unabhängige Existenz besitze.

In der Entwicklung, die um 1600 anhebt und die mit Newton zu einem gewissen Abschluß kommen sollte, vollzieht sich eine tiefgreifende Umwertung der naturphilosophischen Begriffe. Wie sich die Menschen, gegen Ende des Mittelalters, der Natur aufs neue zuwandten, wie sie diese neu ent-

${ }^{44}$ Lichtenberg hat allerdings noch hundert Jahre nach Newton geglaubt, daß ein Gedicht auf den leeren Raum einer großen Erhabenheit fähig wäre. Auch hat er gerade den 90. Psalm nie ohne ein erhabenes unbeschreibliches Gefühl lesen können (Vermischte Schriften 2,34.). 
deckten, sahen sie in ihr, wie in einem Zauberspiegel, auch ihre eigene unbewußte Seele. So erschien der Kosmos beseelt und lebendig, und darum war er wirklich. Mensch und Welt, Mikrokosmos und Makrokosmos, bildeten auf geheimnisvolle Weise ein Ganzes, und zwischen beiden glaubte man eine beständige Wechselwirkung zu erkennen. Diese verglich man gern den Resonanzerscheinungen zwischen gleichgestimmten Saiten ${ }^{45}$. Die alte Idee der Weltseele entsprach diesem Weltgefühl vollkommen und wurde darum zu einer der grundlegenden Ideen der Naturphilosophie. So suchten auch die Alchemisten, in ihrem Opus, die im Stoffe gefangene anima mundi zu erlösen. «Dabei blieb es», wie C. G. JuNc sagt, «stets dunkel, ob die endgültigen Veränderungen im alchemistischen Prozeß mehr im materiellen oder mehr im geistigen Gebiet zu suchen seien.» ${ }^{46}$

Die Belebung der Natur führte aber auch zu einer mächtigen Ausbreitung abergläubischer Vorstellungen und Erlebnisse, die die Kehrseite dieses sonst fast paradiesisch anmutenden Zustandes bilden ${ }^{47}$. Der Hexenwahn, der auch noch bei Henry More eine große Rolle spielt, erreichte ja nicht im Mittelalter, sondern im 17. Jahrhundert seinen Höhepunkt.

Als man es unternahm, das Dunkel zu erhellen, wurde das, was ursprünglich vereinigt war, getrennt. Die innige, gefühlsmäßige Beziehung zur Natur, die in der Idee einer weiblichen anima mundi und in der musikalischen Weltharmonie ihren Ausdruck gefunden, die aber auch ihren schrecklichen Aspekt im Glauben an vom Teufel besessene Frauen deutlich genug offenbart hatte, wurde gelöst. Der Mensch, losgelöst von der Natur, trat ihr als forschender Beobachter gegenüber. Zugleich gewann das Denken über ahnungsvolles Fühlen die Oberhand, so daß Descartes das Wesen des Seelischen im Denken zu erkennen glaubte. Der denkenden Seele wurde die räumliche Welt gegenübergestellt als das von ihr wesentlich Verschiedene. Diese Welt war nicht mehr beseelt und lebendig, aber darum nicht weniger wirklich. Denn sie befand sich im Raume und in der Zeit, und diese waren wirklich im höchsten Sinne.

Der Raum ist ja nicht nur anschaulich unmittelbar gegeben, sondern er ist auch der Gegenstand der Geometrie. Und die Naturgesetze, die das Geschehen der räumlichen Welt regeln, sind mathematische Gesetze. In der

${ }^{45}$ Kurt SAlecker, op. cit., S. 100.

${ }^{46}$ C. G.Jung, Psychologie und Alchemie, S. $381 \mathrm{ff}$. (2. Auflage, Zürich 1952).

47 Siehe hiezu z. B. Jaсов Burckhardt, Kultur der Renaissance, 6. Abschnitt. Man erinnere sich, daß die Hexenbulle InNozenz' VIII. 1484, der Malleus malificarum (Hexenhammer) 1489 datiert sind. 
Mathematik aber ist unser Geist, im Sinne Platos, einer göttlichen und ideellen Wirklichkeit teilhaftig.

Dahin weisen die Worte von Newtons Lehrer, IsaAc BARrow ${ }^{48}$ : «Mein Gott, inwiefern bist Du denn ein Geometer? Weil, da doch diese Wissenschaft grenzenlos ist, da in Ewigkeit in ihr immer Raum für die Entdeckung neuer Theoreme bleiben wird, selbst für den Menschengeist, Du dies alles in einem Blick übersiehst. Und Du brauchst keine Schlußketten noch mühsame Beweise. Und wenn unser Verstand sonst auch fast nichts vermag, wenn er oft mehr der tierischen Phantasie gleicht, ja gar in unsicheren Träumen befangen ist, wo es dann fast ebensoviel Meinungen wie Menschen gibt: in der Mathematik sind alle einig. Hier vermag der menschliche Geist etwas, ja sogar etwas Ungeheures und Wunderbares ...» Gott, der Geometer, der allen Dingen Maß und Zahl gesetzt hat, erzeugt auch den Raum und die Zeit. Diese sind darum meßbare Größen, also sind sie wirklich.

So betonte auch Henry More, daß der Raum unter anderm darum von der Materie verschieden sein müsse, weil auch ein leerer Raum eine bestimmte Abmessung habe.

Leibniz hat Newton gegenüber die Ansicht verfochten, daß Raum und Zeit nichts Substanzielles, sondern reine Relativbegriffe seien, die der Ordnung der an sich nicht räumlich zu denkenden Substanzen entspringen.

Darauf ließ nun Newton durch seinen treuen Schüler CLARKE antworten $^{49}$ : «Ich hatte mich darauf gestützt, daß Raum und Zeit Größen seien, Lage und Ordnung dagegen nicht. Darauf hat man geantwortet, auch die Ordnung habe ihre Größe, es gäbe vorhergehende und folgende Glieder, es gäbe Entfernung und Abstand in ihr. Darauf erwidere ich, daß das Früher und Später der Glieder ihre Ordnung oder Reihenfolge ausmacht; daß aber die Entfernung, der Abstand oder die Größe der Zeit oder des Raumes, worin ein Ding dem anderen folgt, von der gegenseitigen Beziehung oder Ordnung der Inhalte gänzlich verschieden ist und keine Größenbestimmung dieser Beziehung oder Ordnung selbst begründet. Die Beziehung oder Ordnung kann bei sehr verschiedener Größe der Zeit oder des Raumes, der dazwischen liegt, genau dieselbe sein.»

In diesen Worten wird sehr stark der metrische Charakter des Raum-ZeitBegriffs betont und hervorgehoben, daß innerhalb der LeIBnizschen Raum${ }^{48}$ The Works of the Learned J. Barrow, im Lebenslauf von Aвr. HiLl.

49 5. Schreiben Clarkes an Leibniz, Nr. 54 (G. W. Leibniz, Philosophische Werke, herausgegeben von A. Buchenau und E. Cassirer, Leipzig 1924). 
Zeit-Lehre, die nur topologisch ist, keine Möglichkeit besteht, in vernünftiger Weise den Abstand zweier Punkte zu definieren.

Der metrische Charakter ist nun auch in unserer heutigen Beschreibung von Raum und Zeit das wesentliche Motiv. Raum und Zeit werden nämlich in der allgemeinen Relativitätstheorie, die bis jetzt das letzte Glied in einer jahrhundertelang dauernden Entwicklung ist, als «Metrisches Feld» dargestellt, welches den Abstand sehr nahe benachbarter Punkte festlegt. Dieses Feld, oder die ihm zugeordneten metrischen Komponenten $g_{i k}$, haben eine absolute Bedeutung (mathematisch drückt sich dies darin aus, daß $g_{i k}$ Tensorkomponenten sind), d. h. man kann von ihnen sprechen, ohne auf das Vorhandensein von Materie zu achten. Auch ein völlig leerer Raum hat eine wohlbestimmte geometrische Struktur und in diesem Sinne kann man ihn als «absoluten Raum» bezeichnen. Die geometrische Struktur des Raumes bestimmt den Ablauf der in ihm vor sich gehenden physikalischen Erscheinungen, wobei diese ihrerseits auf die Raumgeometrie zurückwirken. Diese Rückwirkungen, die sich physikalisch als die Wirkungen der Schwerkraft äußern, unterscheiden freilich den Raum der allgemeinen Relativitätstheorie vom absoluten Raume Newtons. Raum, Zeit und Materie sind nun inniger verbunden, aber diese Verbindung reicht nicht hin, um dem metrischen Kontinuum, als das hier Raum und Zeit erscheint, seine selbständige logische und physikalische Bedeutung zu rauben.

Wir erkennen also, daß in einer ganz wesentlichen Hinsicht der Raum noch immer das ist, was er anfangs war: der Allumfasser, in dem sich alles regt und bewegt. Und wenn in unseren Tagen Pasqual Jordan ${ }^{50}$, in einer Verallgemeinerung der EinsteInschen Theorie, den Raum als einemetrische Mannigfaltigkeit auffassen möchte, in der spontan immer neue Sternenwelten erzeugt werden, so sehen wir, daß selbst der Gedanke, ihn mit dem alten Schöpfergott zu identifizieren, noch nicht ganz verblaßt ist. Der Aufstieg des Raumes zu göttlicher Höhe ist ein Zeichen dafür, daß die Welt der mathematischen Begriffe und Symbole zum Repräsentanten der Wirklichkeit wurde. Maß und Zahl, der abstrakte Beziehungsreichtum der mathematischen Gebilde, sie verdrängten die bunte, gefühlstiefe und oft auch unheimliche Bilderwelt der alten Naturphilosophie. Wenige wurden sich aber des damit verbundenen Verlustes bewußt. Diese wenigen waren jedoch nicht in der Lage, den Sinn jener alten Symbole einer neuen Generation klarzumachen, denn es fehlte ihnen ein Licht, das das geheimnisvolle Dun-

50 P. Jordan, Die Herkunft der Sterne (Stuttgart 1947); Schwerkraft und Weltall (Braunschweig 1952). 
kel erleuchtet hätte. Wie die Polemik zwischen Keplen und Fludd zeigt, die wohl ein klassisches Beispiel hierfür bietet, fehlte ihnen jedes Verständnis für den Sinn und die Macht der neuen Wissenschaft ${ }^{51}$. Wenn also jene, die mathematisch zu denken vermochten, sich über die Wahrheit in einem nie gekannten Maß einigen konnten, so war dafür allen anderen jedes Verständnis ungeheuer erschwert, ja verunmöglicht.

Darum zieht sich durch das Weltbild der neuen Zeit ein tiefer Bruch. Die Außenwelt ist von der Innenwelt geschieden; der forschende Mensch und seine Geisteswelt, sie stehen außerhalb des Naturzusammenhangs obwohl doch die Naturwissenschaften geistige Schöpfungen des Menschen sind, die nicht nur von außen stammen können. Die wissenschaftlichen Theorien sagen nur den wenigen etwas, die in ihren Zauber einzudringen vermögen. Allzuviele aber verfallen einer fast abergläubischen Verehrung der wissenschaftlichen Möglichkeiten.

Daß dieser Zustand ein Übel sei, ist zwar immer wieder empfunden worden ${ }^{52}$. Goethe hat es schon als junger Mann gefühlt. Seine mephistophelischen Worte:

Wer will was Lebendigs erkennen und beschreiben,

Sucht erst den Geist heraus zu treiben,

Dann hat er die Teile in der Hand,

Fehlt leider! nur das geistige Band.

Encheiresin naturae nennt's die Chemie,

Spottet ihrer selbst und weiß nicht wie.

Faust, 1. Schülergespräch

scheinen geradezu auf die von uns beschriebene Entwicklung hinzuweisen. Aber die Empfehlung des gereiften Dichters:

Müsset im Naturbetrachten

Immer eins wie alles achten;

Nichts ist drinnen, nichts ist draußen,

Denn was innen, das ist außen.

So ergreifet ohne Säumnis

Heilig öffentlich Geheimnis.

Gott und Welt, Epirrhema zu Die Metamorphose der Pflanzen

${ }^{51}$ W. PAUli, Der Einfluß archetypischer Vorstellungen auf die Bildung naturwissenschaftlicher Theorien bei Kepler (C.G. Jung und W.PAuli, Naturerklärung und Psyche, Zürich 1952).

${ }^{52}$ Siehe zum folgenden auch W.PAULI, op. cit., S. $161 \mathrm{ff}$. 
kann uns nicht direkt weiterhelfen, denn, obwohl öffentlich, so ist das, was wir ergreifen sollen, eben doch noch ein Geheimnis.

Dieses zu offenbaren ist bisher niemandem geglückt, wenn auch in der neuesten Physik sich die Zeichen mehren, daß etwas in dieser Richtung zu geschehen hat.

In der Quantentheorie nämlich ist es nicht mehr möglich, von der Tatsache, daß ein Naturvorgang nur durch Beobachtung wahrgenommen werden kann, zu abstrahieren. Die Art der Beobachtung und des Beobachtungsmittels gehen in die Naturbeschreibung ein, und diese verliert dadurch ihren absoluten, d. h. vom Beobachter unabhängigen Charakter. Da jener in der Wahl seiner Mittel eine große Freiheit besitzt, geht dabei der durchgängig deterministische Zug der klassischen Physik verloren und an seine Stelle treten statistische Gesetze.

Die Idee komplementärer Gegensatzpaare, die wir notwendig brauchen, um die Quantentheorie sinnvoll deuten zu können, ist überdies ein Beispiel für die Art, wie Gegensätze ein Ganzes bilden können, ohne sich dabei aufzuheben. Schon in der Physik geschieht dies freilich mit Hilfe einer mathematischen Funktion, die keine unmittelbare, direkte Bedeutung besitzt. Zudem ist die bestehende Quantentheorie noch sehr unvollständig, da es nicht gelungen ist, sie im Sinne der Relativitätstheorie zu verallgemeinern.

Wir glauben darum, daß die Idee der Komplementarität einer weiteren, großen Vertiefung und Verallgemeinerung bedarf, bevor ein Schritt zur symbolischen Vereinigung der nun getrennten Welten möglich wird. Wie wir verallgemeinern müssen, was jene Vertiefung bedeuten soll, darüber wissen wir vorerst noch nichts.

\section{Freiheit und Naturgesetze}

Ich möchte zum Schluß noch einen Gedankenkreis betrachten, der seit Patrizzi mit der neuen Raumlehre aufs engste verflochten erscheint, wenn er auch rein begrifflich keinen unmittelbaren Zusammenhang mit ihr hat.

Wir haben gesehen, wie PATrizzi und Bruno davon schwärmen, daß die Sterne, gleich Vögeln in der Luft, frei im Äther schweben, und bei Bruno wird das Gefühl großer Befreiung aus der Umklammerung durch die starren Sphären zum entscheidenden Motiv seiner Begeisterung. Das neue Weltbild, so hoffte er, sollte die Freiheit und Beseeltheit des Universums wissenschaftlich begründen. Und im gewissen Sinne empfanden More und NEWToN noch genau gleich. 
Darum hat More die calvinistische Prädestinationslehre nie annehmen können, die ihm wider die Freiheit aller beseelten Wesen zu sprechen schien. Er hat darum den Versuch gemacht, auf seine Weise die Idee der Allwissenheit und Vorsehung Gottes und die der Freiheit und Verantwortung der Menschen zu vereinigen. Dazu diente ihm einerseits eine poetische, stark gefühlbetonte Schau, in der das neue Weltbild auch als ethisch bedeutsam dargestellt wird. Dies geschieht vor allem durch die ausführliche Erzählung eines Traumes in den Divine Dialogues, die wir im Anhang vollständig mitteilen. Denn in dieser Erzählung wird die Geisteshaltung Mores, wie kaum in einem anderen Text, deutlich. Wir verspüren etwas von dem Zauber, der von dem phantasievollen Mann ausgegangen ist, aber es wird uns auch die Beschränkung seines Denkens deutlich.

Der Traum soll die Frage beantworten, wieso, in einer von einem guten und weisen Gotte geschaffenen und regierten Welt, so viel Böses geschehen kann. Zur Lösung dieses Rätsels werden dem Träumer die «beiden Schlüssel der Vorsehung» überreicht. Diese erschließen die Geheimnisse der physikalischen und der ethischen Welt. Der erste, silberne Schlüssel verhilft zur Kenntnis des wahren, d. h. des kopernikanischen Weltsystems. Sein Motto ist: «Schließe die Fenster, auf daß es im Hause tage.» Dieses Motto ist zweideutig: Man kann es als mystische Regel auffassen, wonach das Abwenden von der Außenwelt zu innerer Erleuchtung führt. Aber man kann es auch dahin deuten, daß nur derjenige, der nicht dem Augenschein, sondern der inneren Logik und Vernunft traut, die Wahrheit der heliozentrischen Lehre erkennt. Ein solcher wird einsehen, daß die Sonne das Zentrum der Welt sein muß, und darum tagt es in seinem Hause.

Das Motto des zweiten Schlüssels lautet: «Die Liebe zu Gott ist das Licht der Seele.» Durch ihn lernt der Träumer den Emanationsprozeß der Welt und der Seelen aus Gott kennen. Dieser Prozeß erinnert zum Teil an denjenigen, der durch Patrizzi geschildert wird. Physikalisch und ethisch erscheint wie bei diesem, das Licht als zentrales Symbol und vermittelt so zwischen beiden Welten. Die merkwürdige Wendung Newtons in seinem Scholium generale: «Und wenn die Fixsterne die Zentren ähnlicher Systeme sind, sind auch sie alle ähnlich gebaut und unterstehen dem Gebote eines Einzigen: zumal da das Fixstern- und das Sonnenlicht dieselbe Natur haben und alle Systeme sich gegenseitig Licht zustrahlen», weist ebenso auf die symbolisch-vereinigende Kraft des Lichtes hin.

Gleichwohl wird man kaum den Eindruck gewinnen, daß die beiden Schlüssel das alte Problem, woher das Böse stamme, lösen können. Das 
überraschende Ende des Traumes scheint mir wie ein Protest der dunklen Tiernatur, die unsern Philosophen aus seinen allzu luftigen und lichten Spekulationen aufschreckt.

Andererseits hat More auch durch mehr logische Erwägungen seine Auffassung zu begründen versucht. Ihnen widmete er einen längeren Abschnitt seiner Dialoge ${ }^{53}$.

Er kommt dabei zum Schluß, daß auch Gott nicht zum voraus wisse, wie sich der frei Entscheidende entscheiden werde. Dieses Nichtwissen ist aber keine Unvollkommenheit an Gottes Allwissenheit. Die Vollkommenheit des Wissens besteht ja darin, die Dinge so zu wissen, wie sie ihrer Natur nach sind. Wenn aber Gott von einem frei handelnden Wesen weiß, daß es wählen kann, wie es will, so ist dies das vollkommenste Wissen, das über dessen Handlungen möglich ist, bis zu dem Augenblick, wo es sich völlig entschieden hat. Würde man jemanden für determiniert halten, während er frei ist, so wäre das kein Wissen, sondern Irrtum ${ }^{54}$.

Auch Newton scheint so gedacht zu haben, und darauf weist seine Formulierung, Gott wisse alles, was gewußt werden könne. Daraus folgt ja, daß es Dinge gibt, die überhaupt nicht wißbar sind. Dieses nicht Wißbare sind eben die Entscheidungen freier Wesen, die, wenn sie eintreten, eine neue Situation schaffen. Auch Gott ist frei und greift darum tätig in den Weltlauf ein.

LEIBNIZ ${ }^{55}$ hatte hiegegen eingewandt, daß nach dieser Ansicht Gott nicht genügend Einsicht besessen habe, um der Welt immerwährende Bewegung zu verleihen, und darum müsse er sie, wie eine $\mathrm{Uhr}$, von Zeit zu Zeit aufziehen.

Darauf antwortet Newton: «Wenn man sich die Welt als eine große Maschine vorstellt, die ohne Eingriff Gottes weitergeht, so führt dies zum Materialismus und Fatalismus und zielt - unter dem Vorwand, Gott zu einem überweltlichen Verstandeswesen zu machen - darauf ab, die göttliche Vorsehung und Leitung tatsächlich aus der Welt zu verbannen.»

${ }^{53}$ Div. Dialog. 1, 20.

${ }^{54}$ Diesen Gedankengang konnte More bei Boetrus, Consolationis Philosophiae Lib. V. 4. 116 lesen: quodsi, quae incerti sunt exitus, ea quasi certa providentur, opinionis id esse caliginem, non scientiae veritatem. Boetius lehnt jedoch schließlich (V. 5. 121) diesen Gedanken als allzu menschlich ab. Im höchsten, göttlichen Wissen gibt es auch eine Vorkenntnis dessen, was keinen icheren Ausgang hat. Somit wird hier die menschliche Logik nicht als bindend anerkannt, ebenso wie es PLAto für ein bloßes Meinen hält, daß alles einen Ort haben müsse und daher räumlich sei.

${ }^{55}$ Siehe hiezu und zum Folgenden die Streitschriften zwischen Leibniz und Clarke. Die Briefe Clarkes sind von NEwToN entworfen worden. 
Leibniz war der Ansicht, Newton nehme hier offenbar zum Wunder seine Zuflucht, was unwissenschaftlich sei, oder aber er mache Gott zur Weltseele, und das sei unchristlich.

Diesen Schluß hat aber Newton nicht anerkannt: «Für Gott sind Natürlich und Übernatürlich nicht im geringsten voneinander verschieden. Diese Unterschiede gelten nur für unsere Art, die Dinge zu sehen.» Er meinte, daß uns das natürlich erscheine, was regelmäßig geschieht. Was jedoch nur selten eintritt, das scheint uns ein Wunder. Ferner war er der Ansicht, daß die Weisheit Gottes nicht darin bestehe, den gegenwärtigen Bau der Welt zu verewigen ${ }^{56}$, sondern ihn so lange dauern zu lassen, als er es für gut halte. Auch sagte er: «Gott handelt jederzeit in der regelmäßigsten und vollkommensten Art. Es gibt in seinem Werke keine Unordnung. Die gelegentlichen Änderungen, die er im Bau der Dinge vornimmt, liegen nicht außerhalb der allgemeinen Ordnung. Bei Dingen, die in sich selbst durchaus gleich und indifferent sind, kann sich der göttliche Wille frei und von selbst bestimmen, ohne daß ihn irgendeine Ursache antreibt, und diese Fähigkeit bedeutet eine Vollkommenheit Gottes.»

Wir sehen hier, daß Newton den Naturgesetzen keine zwingende Gewalt zuschreiben wollte. Sie sind empirisch gefunden und geben das wieder, was in der Regel geschieht. Sie haben auch keine ewige Geltung, wie auch Gott den Bau der Welt nicht verewigen will. Damit wird versucht, die Welt als eine beständig werdende, sich im Fluß der Zeit entwickelnde zu sehen. Die Zeit wird damit zu einer Schöpfungsordnung, wie sie ja auch das Attribut der ewigen Dauer des Schöpfergottes ist.

Es bleibt aber gerade darum unklar, worin das regelmäßige Handeln Gottes besteht und was das Wesen der Allgemeinen Ordnung sein soll, von der Newton spricht. Diese Ideen sind auch nicht recht mit der logischen Struktur der klassischen Mechanik, d.h. mit der durch Newton geschaffenen Physik zu vereinigen. Spätere Generationen haben darum die Mechanik in «materialistischer und fatalistischer» Weise aufgefaßt und die Welt als eine große Maschine betrachtet, die ohne den Eingriff Gottes weitergeht.

Ich vermute, daß auch Newton geahnt hat, daß dies letzten Endes die notwendige Folge seiner physikalischen Forschungen sein werde.

Wenige Jahre nach der Abfassung der Principia ist er, wie wir erwähnt haben, einem Zustande tiefster Depression verfallen. Damals warf er seinem Freunde Locke, dem Philosophen, u. a. vor, er sei ein «Hobbist», was Ma-

${ }^{56}$ Vergleiche hiezu die oben angeführte Aussage Mones, daß Gott aufbaut und zerstört, wie es ihm beliebt. 
terialist und Atheist bedeutet, weil er die eingeborenen Ideen leugne. Dieser Vorwurf war insofern begründet, als Locke in hohem Maße die theologischen und philosophischen Ansichten Newtons teilte. Dieser sah somit den Splitter im Auge seines Nächsten, während der Balken im eigenen Auge wohl mit ein Grund seiner Depressionen war.

Schließlich ist es Newton aber offenbar gelungen, seinen Glauben an die Vorsehung, die Endursachen und die Herrschaft Gottes zu retten, mußte aber eine gewisse Widersprüchlichkeit seiner Philosophie in Kauf nehmen und die Einsicht, daß die Mechanik doch nicht die umfassende Wissenschaft sei, die ihm vorgeschwebt hatte. Die Probleme, mit denen er gerungen hatte, waren damit aber nicht aus der Welt geschafft.

Seine Nachfolger haben - wenn man will, folgerichtig - die theologischen Ideen aus der Physik verbannt, und so blieb, wie dies schon Newton richtig erkannt hatte, nichts als die Natur und das Fatum.

Dieses Fatum stellt uns aber heute erneut vor die ernste Frage nach der Freiheit und Verantwortung der wissenschaftlich forschenden Menschen.

\section{Anhang 1: Patrizzi}

Francisci Patritii Panaugia Liber Primus de Luce, Salvatis anno 1583 aetatis suae 58.

Franciscus Patritius Novam, Veram, Integram, de universis conditurus Philosophiam, sequentia, uti verissima, pronuntiare est ausus. Pronuntiata, ordine persecutus, Divinis oraculis, Geometricis necessitatibus, Philosophicis rationibus, clarissimis experimentis comprobavit

Ante Primum, nihil.

Post Primum, omnia.

A Principio, omnia.

Ab Uno, omnia.

A Bono, omnia.

A Deo, Uno Triuno omnia.

Deus, Bonum, Unum, Principium, Primum idem.

Ab Uno, unitas primaria.

Ab Unitate primaria, Unitates omnes.

Ab Unitates, Essentiae

Ab Essentiis, Vitae.

A Vitis Mentes ${ }^{57}$.

A Mentibus, Animi.

${ }^{57}$ Mens: Das 17. Buch der Panarchia handelt «de creatis Mentibus». Es heißt dort, daß bei Paulus, Dionysius Noas und in der hebräischen Tradition «mentes» die Engel, Erzengel, Prinzipate, Tugenden, Kräfte und Throne bedeute. Dazu kommen, als speziell hebräisch die $3 \times 3$ Klassen der 
Ab Animis, Naturae.
A Naturis, Qualitates.
A Qualitatibus, Formae.
A Formis, Corpora.
Haec omnia sunt in Spacio.
Haec omnia sunt in Lumine ${ }^{58}$.
Haec omnia sunt in Calore.
Per haec paratur ad Deum reditus.
Hic Finis et scopus nostrae huius Philosophiae, esto germanus.

Inaudita haec a seculis forsan omnibus et axiomata, et paradoxa, certissimis constare rationibus, ut demonstremus, in hunc modum philosophemur.

Philosophia studium est sapientiae. Sapientia, universitatis est cognitio. Rerum universitas, constat ordine. Ordo priore constat et posteriore. Si quis a posteris philosophari coeperit, rerum ordinem confunderit, eisque sibique tenebras offunderit. A primis ergo philosophandi initium nobis esto. A primis, cognitisne? an ab incognitis? Si ab incognitis incipiamus, sequentia, incognita erunt omnia. De incognitis nulla nobis condetur Philosophia. A cognitis ergo initium sumendum. Cognitio omnis, a mente primam originem: a sensibus exordium habet primum. Inter sensus, et naturae nobilitate, et virium praestantia, et actionem dignitate, visus est primarius. Visui prima, et primo cognita, sunt lux, et lumen. Eorum ope, et opera, plurimae patescunt rerum differentiae. Lux, et lumen, statim natis, se se offerunt. Per haec, prisci homines, sublimia, et media, et ima conspexerunt. Conspecta, sunt admirati. Admirando, sunt contemplati. Contemplando sunt philosphati. Philosophia ergo, lucis, luminis, admirationis, contemplationis proles est verissima. A luce ergo, eiusque prole lumine, rerum sensibilium praestantia omni primis, primarioque sensui, primo cognitis, Philosophiae nostrae iaciamus fundamenta. Quod si Philosophi veteres fecissent, nec ignota sensibus, ac mentibus omnibus, Chaos, Homoeomerias, Atomos, Materias primas, secundasve, rerum prinicipia statuissent; nec in tantas ipsi dissensiones venissent: neque in abyssum tenebrarum, philosophiam coniccissent. Lux ergo, et lumen primaria eius proles,

\section{Cherube, Seraphe, Chasmatin, \\ Hagor, Arabim, Tarsitim, \\ Ophatim, Thephsaim, Isim.}

Ich habe darum «mentes», was "Geist», "Verstand» bedeutet, in unserem Text mit «Engel» wiedergegeben. Ferner vergleiche man die Seins-Stufen Ficinos (Theologia Platonica III. 1.): Deus Angelus, Anima, Qualitas, Corpus.

${ }^{58}$ Lumen: PatrizzI unterscheidet «lux» und «lumen». Im 4. Buch der Panaugia, «de Lumine», wird erklärt, daß vom Licht (lux) die Strahlen (radii) in Strahlenkegeln ausgehen. Die Strahlen sind blendend hell. Aus ihnen entsteht die Helligkeit (lumen), ein milderes Licht, welches die Strahlen umschwebt und begleitet. Daß dem so sei, sagt Patrizzi, lehre der Augenschein. - Aus diesen Erklärungen folgt, daß «Lux» in erster Linie die Lichtquelle bedeutet, während «Lumen» das, als diffuses Streulicht, den ganzen Raum erfüllende Licht ist. Darum haben wir «lumen» mit «Helligkeit» wiedergegeben. 
ante omnia sunt nobis cognoscenda. Per ea, ad primam lucem, patremque luminum ascendendum. Apud eum tantisper commorandum. Ab eoque res omnes deducendae. Per deductas, ad eum iterum revertendum: ut apud eum mansionem perpetuam faciamus.

A luce igitur, et lumine, quae nos maxime admiramur, exordium sumamus. A luce inquam, quae Dei ipsius, eiusque bonitatis est imago. Quae omnem supramundanam, omnem circamundanam, omnemque mundanam, illustrat regionem. Quae se se per omnia extendit. Per omnia se fundit. Per omnia permeat, omnia permeando format, et efficit. Omnia vivificat. Omnia continet. Omnia sustinet. Omnia congregat. Omnia unit. Omnia disgregat. Omnia quae vel sunt, vel illuminantur, vel calescunt, vel perficiantur, vel moveantur, ad se convertit. Conversa purgat. Omnia perficit. Omnia renovat. Omnia conservat: et ne in nihilum abeant, efficit. Omnium rerum est et numerum et mensura. Lux rerum omnium purissima. Inalterata, inalterabilis: Impermista, imperimiscibilis: Indomata, indomabilis. Nullius indiga. Dives omnium. Ab omnibus optata: Omnibus optabilis. Coelorum ornamentum. Ornamentum corporum omnium. Mundi decor. Mundi pulchritudo. Mundi gaudium. Mundi risus. Qua, aspectui nihil incundius. Nihil animo laetius. Nihil vitae commodius. Nihil cognitu praestantius. Nihil ad agendum utilius. Sine qua, iacerent in tenebris, inertia sibi ipsis omnia, nobisque incognita.

Hanc ergo lucem contemplationis primariam causam, contemplando prosequamur, et propositorum probationes exordiamur.

Um zu beweisen, daß diese wohl noch in keinem Jahrhundert erhörten, von allem gewohnten abweichenden Axiome auf den sichersten Gründen ruhen, lasset uns also philosophieren:

Die Philosophie ist das Studium der Weisheit. Die Weisheit ist die Erkenntnis der Allgesamtheit. Die Allgesamtheit der Dinge beruht auf Ordnung. Die Ordnung beruht auf dem Früher und Später. Wer vom Späteren ausgehend zu philosophieren begänne, würde die Ordnung der Dinge verwirren und über sie und sich Dunkelheiten ausbreiten. Von den ersten Dingen nehme daher unsere Philosophie ihren Anfang. Von den ersten Dingen, die bekannt sind, oder von den ersten unbekannten Dingen? Wenn wir vom Unbekannten her anfangen, wird auch alles Folgende unbekannt sein. Vom Unbekannten her können wir keine Philosophie begründen. Lasset uns daher mit dem Bekannten anfangen. Alle Erkenntnis nimmt vom Geiste her ihren ersten Ursprung, bei den Sinnen hat sie ihren ersten Anbeginn. Unter den Sinnen ist das Gesicht der Erste, denn seine Natur ist die vornehmste, seine Kraft die größte, seine Tätigkeit die würdigste. Dem Gesicht sind das Erste und das zuerst Erkannte: Licht und Helligkeit. Mit ihrer Hilfe und durch ihr Wirken erhellen die meisten Unterschiede der Dinge. Licht und Helligkeit bieten sich dem Neugeborenen dar. Durch sie erblickten die Menschen der Frühzeit das, was in den hohen, den mittleren Regionen und in den Tiefen ist. Dieser Anblick führte zur Bewunderung. Indem sie bewunderten, kamen sie zur Betrachtung. Aus der Betrachtung philosophierten sie. Darum ist die Philosophie der wahre Sprößling des Lichtes, der Helligkeit, der Bewunderung und der Betrachtung. Darum legen wir die Fundamente unserer Philosophie ausgehend vom Lichte und von seinem Sprößling, der Helligkeit, die an Vorzüglichkeit die ersten sind von allen Sinnendingen und vom vorzüglichsten Sinne zuerst erkannt werden. Wenn das die alten Philosophen getan hätten, sie hätten nicht die ganz unsinnlichen und unverständlichen Vorstellungen, wie Chaos, Homöomerien, primäre und sekundäre Materien, als Prinzipien der Dinge aufgestellt; sie wären nicht so uneinig miteinander geworden und sie hätten die Philosophie nicht 
in den Abgrund der Dunkelheiten gestürzt. Das Licht also, und seinen vorzüglichsten Sprößling, die Helligkeit, müssen wir vor allem erkennen. Durch sie müssen wir zum ersten Licht und zum Vater der Helligkeiten aufsteigen. Bei ihm werden wir eine Zeit verweilen. Von ihm sind alle Dinge abzuleiten. Vom Abgeleiteten müssen wir wieder zu ihm zurückkehren: auf daß wir bei ihm eine dauernde Wohnstatt finden.

Vom Lichte also und der Helligkeit, die wir aufs höchste bewundern, laßt uns beginnen. Vom Lichte, sage ich, das Gottes und seiner Güte Abbild ist. Das jede Gegend über der Welt, um und in der Welt erhellt. Das alles durchdringt und, alles durchdringend, alles gestaltet und bewirkt. Das alles belebt, alles enthält, alles unterhält, alles eint, alles zerstreut. Das alles, was ist, was erleuchtet, erwärmt, vollendet und bewegt wird, zu sich bekehrt. Das Bekehrte reinigt. Alles vollendet und erneuert. Das alles erhält, auf daß es sich nicht im Nichts verliere. Es ist aller Dinge Zahl und Maß. Das Licht ist das reinste aller Dinge: unverändert, unveränderlich; ungemischt, unvermischlich: unbezwungen, unbezwinglich. Von nichts abhängig, ist es reich an allem. Von allen erwünscht, ist es allen wünschbar. Der Himmel Zierde, aller Körper Zier. Schmuck der Welt. Schönheit der Welt. Freude der Welt. Lachen der Welt. Nichts ist erfreulicher anzusehen. Nichts erheitert den Geist mehr. Nichts ist fürs Leben angenehmer. Nichts herrlicher zu erkennen. Nichts zum Wirken nützlicher. Ohne es läge alles, für uns unerkennbar, in dumpfer Faulheit.

Darum lasset uns in der Betrachtung des Lichtes, aller Betrachtung erstem Grunde, fortfahren, und mit dem Beweise des Gesagten beginnen.

\section{Pancosmias lib. I. De Spacio Physico}

Quid autem illud fuit, quod summus opifex primum omnium extra se produxit? Quid aut debuit, aut expediit prius produci, quam id quo omnia alia, ut essent eguerunt, et sine quo esse non potuerunt, ipsum autem sine aliis esse poterat, et aliorum nullo eguit ut esset. Id enim ante alia omnia necesse est esse, quo posito alia possi possunt omnia: quo ablato, alia omnia tollantur. Nam sine quo aliorum nihil est, et id sine aliis possit esse, necessario primum est, inquit Aristoteles quoque. Id autem spacium est.

Omnia namque et corporea, et incorporea, si alicubi non sint nullibi sunt, si nullibi sunt, neque etiam sunt. Si non sunt, nihil sunt. Si nihil sunt, neque animae neque naturae, neque qualitates, neque formae, neque corpora erunt. At hosce esse rerum gradus extra profundum, iam antea est dictum. Si haec non sint, iam nulla rerum extra profundum erit universitas. At id contra sensum, contra omnem est rationem. Ergo hi rerum gradus sunt; si sunt, nullibi non sunt. Sunt ergo alicubi, sunt ergo in loco, sunt ergo in spacio, aut longo, aut lato, aut profundo, aut duobus horum aut in tribus. Spacium ergo ante haec omnia est. Et eo illa ut sint indigent, ipsum vero, ut sit, illorum indiget nullo. Amici quidam nostri e Peripato, cum duos a nobis libellos editos de spacio legissent, suaviter nos subsannarunt. Quoniam nihil tale scripsisset eorum princeps. Ridiculi sane, ac bardi homines, et scriptorum sui principis ignari. Quid enim illi, aliud est locus, quam spacium, longum, latumque ? tametsi in loco profundum, qui proprie magis locus est, ipse ridicule ommiserit? Quid aliud illi est magnitudo, super qua ei fit motus omnis, sursum, deorsum, in latus, in circuitum ? An non credunt, a terra ad coelum esse spacium? Sed hos omittamus. Qui quoniam Aristoteles de novo orbe hihil dixerit, orbem novum esse, minime sibi persuaderi sinunt. Aliis quam talibus ingeniis philosophemur, sensuum testimoniis, rationumque probationibus utamur. Nulla magna nomina exhorreamus. Res ipsas, verumque in rebus, verique causas vestige- 
mus. Veritatem, veritatis gratia inquiramus. Ad rem igitur regrediamur. De corporibus quidem, nihil videtur, cuiquam posse esse dubium, ea esse in loco, hoc est in spacio. Quoniam corpora circumquaque intus et extra, spacio et circundantur et occupantur. Formae vero toto corpore extensae, eamdem trinam occupant dimensionem. Qualitates, calor, frigus, humidum, siccum, molle, durum, reliquas, quis non videt, et extra, et circa, et intra corpora esse protensas? Si vero, natura, de qua postea, per corpora, et ipsa protensa esse reperiatur, et eorum externa attingere, et interna habitare, ipsa quoque in spacio esse erit dicenda. Vita itidem et ea anima, quae sensitiva dicitur, si per instrumenta corporis sit distributa, per spacia erit distributa. Sin vero ratio, et mens animae corpus informet, (quod videtur Aristoteles voluisse, et quo nobis hactenus maxime est dubium) sicuti formae aliae per corpora erunt extensae. Sin vero anima sit in corpore, non ut forma sed ut formatrix, quia corpus in spacio est, ipsa quoque erit in spacio. Sin vero corpus sit in anima, haec si divisibilis sit, in spacio erit divisibili. Si indivisibilis sit, in spacio erit indivisibili. Sed si divinitas universa indivisibilis sit, ut est, in spacio erit indivisibili, et a divisibili spacio circumque erit obvoluta. Si nullibi item sit, sine spacio non cogitatur, si sit alicubi, vel in coeli culmine, vel supra coelum, in spacio certe erit. Si vero sit ubique, in spacio, non esse nequit. Sunt ergo entia cuncta, et ea quae supra entia sunt, in spatio. Et in spacio non esse nequeunt. Igitur antequam entia extra profundum prodirent, spacio eguerunt, quo ipsum est circumvolutum, ut extra ipsum prodirent, et consisterent, si entia esse aut debuerunt, aut potuerunt. Itaque spacium, a primo uno, ante entia alia omnia est profusum, et veluti spiritu oris eius efflatum atque diflatum in finitum, atque infinitum. Non ergo amplius quaerendum an spacium in rerum sit universitate. Sed indagandum, an spacium sit aliquid.

Spacium ergo hoc, quod ante mundum fuit, et post quod mundus est, et quod mundum et capit, et excedit, quidnam tandem est? Aptitudo ne simplex ad capienda tantum corpora est, et aliud nihil? Suscipit quidem spacium hoc corpora omnia, sed non videtur, aliud nihil esse, quam aptitudo. Sane, si quicquam rerum sit, vel substantia est vel accidens. Et si substantia est, vel incorporeum quid est, vel corpus. Si vero accidens, vel quantitas, vel qualitas, vel aliud quid tale. Profecto dicimus nos, spacium per se ipsum, cum mundum praecedat, cumque extra mundum sit, nihil rerum esse mundanarum, praeter eam eius partem, quae mundum capit, aut quod mundum suo corpore occupat, verum alia res, a mundo diversa est. Mundus enim corpus est, spacium vero corpus minime est, nulla ergo categoriarum spacium complectitur, ante eas omnes est, extra eas omnes est. Quid ergo est ? hypostasis, diastema, est, diastasis. Ecstasis est, extensio est, intervallum est, capedo est, atque intercapedo. Ergo quantitas? Ergo accidens? Ergo accidens ante substantiam? et ante corpus? Architas uterque, et senior Pythagorae auditor, et iunior Platonis amicus, et qui eos secuti sunt Scriptores categoriarum, hoc spacium non cognovere. Sed sunto categoriae in mundanis bene positae, spacium de mundanis non est; aliud quam mundus est. Nulli mundanae rei accidit, sive ea corpus sit, sive non corpus, sive substantia, sive accidens, omnia hae antecedit; omnia illi uti accidunt, sic etiam accidunt; ita ut non solum quae in categoriis numerantur accidentia, verum etiam quae ibi est substantia, illi sunt accidentia. Itaque aliter de eo philosophandum, quam ex categoriis. Spacium ergo extensio est hypostatica, per se substans, nulli inhaerens. Non est quantitas. Et si quantitas est, non est illa categoriarum, sed ante eam, eiusque fons et origo. Non ergo accidens dici potest, neque enim cuiquam accidit substantiae. Quid ergo substantia ne est? Si substantia est, id quod per se substat, spacium maxime omnium substantia est. 
Atque utrumque per se substans, per se existens, in se existens, adeo, ut etiam per se stet semper, atque in se stet: neque umquam moveatur, neque essentiam, neque locum mutet, nec partibus, nec toto.

\section{Panarchias, Liber XX. \\ Divinitas, an sit ubique, an nullibi, an alicubi}

Concludendum igitur est verissime, Deum et universam Divinitatem, quia immaterialis, incorporeaque sit, nullam a corporibus, aut materia pati resistentiam. Atque ideo verissimum esse, eam esse ubique; ipso sui esse, ipsa sui potentia, ipsa sui operatione, et omnia tum efficere potuisse, tum effecisse, quaecumque et in terra et in universis elementis, et in coelis, et supra coelos, sunt et visibilia et invisibilia. Et omnia vivificare in omnibus, et omnia operari. Igitur Deus, modis hisce est ubique. Non autem, ut Aristoteles voluit, tantum alicubi, supra coeli culmen, et extra coelum. Et est etiam nullibi, quia nullibi est affixus, nullibi locatus. Sed per omnia means, ab omnibus et segregatus, et ab omnibus seiunctus, in suae dignitatis, et supereminentiae abysso, se se a nostris sensibus etiam cogitationibus, in altum rapuit.

\section{Pancosmia, 1. Buch. Der physikalische Raum}

Was war es aber, was der höchste Werkmeister vor allem anderen zuerst außer sich erschuf? Sollte und mußte nicht dasjenige zuerst geschaffen werden, dessen alles andere bedarf, damit es ist und ohne das es nicht sein kann, und das selber nichts anderes zu seiner Existenz bedarf? Dieses muß vor allem anderen notwendig da sein, und ist es gesetzt, so kann auch alles andere gesetzt werden; nimmt man es aber weg, so wird auch alles andere aufgehoben. Denn das, ohne welches das andere nichts ist und das ohne das andere sein kann, ist notwendig das Erste, sagt auch Aristoteles. Dieses aber ist der Raum.

Alles nämlich, sei es körperlich oder unkörperlich, ist, wenn es nicht irgendwo ist, nirgends, und wenn es nirgends ist, ist es überhaupt nicht. Wenn es aber nicht ist, so ist es nichts. Was aber nicht ist, das ist nicht Seele, nicht Natur, nicht Qualität, nicht Form, noch ist es ein Körper. Daß aber dies die Stufen der Dinge außerhalb des Abgrundes sind, wurde schon früher gesagt. Wenn diese nicht sind, gibt es schon keine Allgesamtheit der Dinge außerhalb des Abgrundes. Das aber ist gegen den Augenschein, ist gegen jede Vernunft. Also gibt es diese Stufen der Dinge; wenn sie sind, sind sie nicht nirgends. Sie sind also irgendwo, sie haben einen Ort und sind also im Raume, oder in der Länge, oder in der Breite, oder in der Tiefe, oder in zweien oder dreien von diesen. Der Raum ist daher vor all dem. Sie brauchen ihn, um zu sein, er aber braucht sie gar nicht, um zu sein. Einige unserer Freunde, die der peripatetischen Schule angehören, rümpften lieblich ihre Nasen, als sie zwei unserer Schriften über den Raum lasen: Da doch ihr Fürst nichts dergleichen geschrieben habe. Das sind lächerliche und tölpelhafte Menschen, und sie kennen die Schriften ihres Fürsten nicht. Was bedeutet denn bei ihm der Ort anderes als der Raum, das Lange und Breite? Dennoch ließ er beim Ort das Tiefe, das doch eigentlich am meisten Ort ist, lächerlicherweise aus. Was bedeutet bei ihm denn jene Größe anderes, über welcher alle Bewegung stattfindet: herauf, herab, in die Breite, im Kreis? Glauben sie denn nicht, es sei ein Raum von der Erde zum Himmel? Aber wir wollen uns um die nicht kümmern, die, weil Aristoteles nichts von der neuen Welt gesagt hat, sich nicht dazu überreden lassen, daß die neue Welt existiere. Für andere als für solche Geister wollen wir philosophieren, das Zeugnis des Augenscheins, die Beweise der Vernunft wollen wir benützen. Vor keinem gro- 
Ben Namen schrecken wir zurück. Die Sache selber, das Wahre in den Dingen, die wahren Gründe suchen wir. Wir streben nach der Wahrheit in den Dingen, die wahren Gründe suchen wir. Wir streben nach der Wahrheit um der Wahrheit willen. Doch zurück zur Sache. Was nämlich die Körper betrifft, da kann man doch offenbar nicht bezweifeln, daß sie einen Ort haben, also im Raum sind. Da ja die Körper überall, innerlich und außen, vom Raum umgeben sind und diesen einnehmen. Die Formen aber, die sich über den ganzen Körper ausbreiten, nehmen mit ihm drei Dimensionen ein. Die Qualitäten: warm, kalt, feucht, trocken, weich, hart und alle übrigen, wer sieht nicht, daß sie außerhalb, um und in den Körpern ausgebreitet sind? Ja auch die Natur, sie ist in den Körpern ausgebreitet, wie sich später ergeben wird, und berührt sie von außen und wohnt in ihrem Inneren, und man muß von ihr auch sagen, sie sei im Raume. Das gilt auch vom Leben und von derjenigen Seele, die man die empfindende nennt; wenn sie durch die Werkzeuge des Körpers ausgebreitet ist, ist sie räumlich ausgebreitet. Wenn aber die Vernunft, und der Geist der Seele, den Körper formt (was, wie es scheint, des Aristoteles Meinung, und was wir darum sehr bezweifeln) so sind sie, wie die anderen Formen im Körper ausgebreitet. Wenn aber die Seele im Körper, nicht als Form, sondern als Gestalterin, wäre, so ist auch sie im Raum, weil der Körper räumlich ist. Wenn aber der Körper in der Seele wäre und diese teilbar, so wäre sie in einem teilbaren Raum. Wenn aber die allgemeine Gottheit unteilbar wäre, wie es ja ist, wäre sie in einem unteilbaren Raum und vom teilbaren Raume rings umhüllt. Wenn sie ferner nirgends wäre, kann man sie ohne Raum nicht denken; wenn sie irgendwo wäre, in Himmelshöhn, oder über dem Himmel, so wäre sie gewiß im Raum. Wenn sie aber überall wäre, im Raume, dann kann sie nicht nicht $\operatorname{sein}^{59}$. So sind also alle Wesen und alle Überwesen im Raume. Und im Raume können sie nicht nicht sein. Darum bedurften alle Wesen des Raumes, bevor sie aus dem Abgrund hervorgingen. Dieser aber ist vom Raum umhüllt, damit die Wesen aus ihm hervorgehen und bestehen konnten, wenn es Wesen geben sollte. Somit ist der Raum, vom Ersten Einen, vor allen anderen Wesen ausgegossen worden, und gleich dem Hauch seines Mundes wurde er ausgeblasen und zerblasen ins Endliche und Unendliche. Darum brauchen wir nicht weiter zu fragen, ob der Raum zur Allgesamtheit der Dinge gehöre. Aber wir müssen erforschen, was der Raum sei.

Dieser Raum also, der vor der Welt war und nach dem die Welt wurde und der die Welt sowohl enthält wie auch überschreitet, was ist er denn? Ist er nur die Fähigkeit, so viele Körper aufzunehmen, und nichts sonst? Der Raum nimmt zwar alle diese Körper auf, aber es scheint nicht, daß er nichts als eine Fähigkeit sei. Gewiß, wenn er ein Ding ist, ist er entweder Substanz oder Akzidens. Wenn er aber Substanz ist, ist er entweder unkörperlich oder ein Körper. Wenn er aber ein Akzidens ist, so ist er entweder eine Quantität oder eine Qualität oder eine andere Eigenschaft. Wahrlich, wir sagen, der Raum an sich, der der Welt vorangeht, der außerhalb der Welt ist, gehört nicht zu den Weltdingen, außer jenem seiner Teile, der die Welt enthält und den sie mit ihrem Körper ausfüllt. Er ist gewiß ein anderes Ding, verschieden von der Welt. Die Welt nämlich ist ein Körper, der Raum ist aber gar kein Körper, und er fällt unter keine Kategorie, er geht allen voran und ist außer ihnen allen. Was ist er denn? Er ist eine Hypostase, ein Diastema, eine Diastase. Er ist eine Ekstase, eine Ausdehnung, ein Intervall, das Fassende und das zwischen dem Gefaßten.

${ }^{59}$ Hiezu vergleiche die Stelle aus dem 20. Buch der Panarchia, das die Frage behandelt, ob Gott überall, nirgends oder irgendwo sei, die wir unten anführen. 
Also ist er eine Quantität, ein Akzidens? Also ein Akzidens vor der Substanz? und vor dem Körper? Die beiden Architas, der ältere, der Schüler des Pythagoras, und der jüngere, der Freund des Plato, und alle von diesen beiden abhängigen Schriftsteller, die von den Kategorien handeln, kennen diese Art Raum nicht. Aber wenn auch die Kategorien den Weltdingen wohl angemessen sind, so gehört der Raum eben nicht zu ihnen; er ist etwas anderes als die Welt. Er gehört keinem der Weltdinge zu, sei dies nun ein Körper oder ein Unkörperliches, eine Substanz oder ein Akzidens; allen diesen geht er voran; sie alle gehören ihm an, und zwar so sehr, daß nicht nur das, was unter den Kategorien als Akzidenzien aufgezählt wird, sondern auch das, was dort als Substanz gilt, seine Akzidenzien sind. Daher muß man von ihm anders als mit der Hilfe von Kategorien philosophieren. Der Raum also ist die hypostasierte Ausdehnung, die für sich besteht und von nichts abhängt. Er ist keine Quantität. Und insofern er doch eine ist, so ist er nicht diejenige, die man unter die Kategorien rechnet, sondern er geht ihr voran und ist ihre Quelle und ihr Ursprung. Man kann ihn darum nicht ein Akzidens nennen, da er keiner Substanz angehört. Was ist denn aber Substanz? Wenn das Substanz ist, was für sich besteht, so ist der Raum am meisten von allem Substanz.

Und wie eine Substanz west und ist er durch sich und in sich. Dies so sehr, daß er auch immer durch sich und in sich besteht: und er bewegt sich niemals, noch ändert er Wesen oder Ort, weder teilweise, noch im ganzen.

Panarchia, 20.Buch

Ob die Gottheit überall, nirgends, oder irgendwo sei

(Schluß des Buches)

Mit größter Sicherheit können wir schließen, daß Gott und die allgemeine Gottheit, da sie immateriell, auch unkörperlich sei und von den Körpern oder der Materie keinen Widerstand erfahre ${ }^{60}$. Und daher ist es ganz sicher, daß sie überall ist; ganz in dem Ihrigen, in ihrer eigenen Macht, in ihrer eigenen Tätigkeit. Sie ist fähig, alles zu vollenden, und sie vollendet alles, was auch immer auf der Erde, in allen Elementen, in den Himmeln und über den Himmeln sichtbar und unsichtbar ist. Und in allem belebt sie alles und wirkt alles. So ist also Gott in dieser Weise überall. Nicht, wie es Aristoteles haben wollte, nur irgendwo, in Himmelshöhen oder jenseits des Himmels. Er ist aber auch nirgends, weil er nirgends festgenagelt ist, keine bestimmte Stelle hat. Aber alles durchdringend, von allem abgeschieden und abgetrennt, im Abgrunde seiner Würde und Hoheit, schwingt er sich von unseren Sinnen, ja von unserem Denken hinweg, in die Höhe.

\section{Anhang 2: Henry More, Der Traum des Bathynous ${ }^{61}$}

Philotheus: Sage mir denn, Hylobares, glaubst du nicht, daß freie Wesen, seien es nun die Geister der Engel oder der Menschen, sich so böse betragen könnten, daß, wenn du

${ }^{60}$ Auch Newton sagt im Scholium generale, daß Gott, obwohl allgegenwärtig, keine Rückwirkungen von den Körpern erfahre. Hinter dieser Idee steht eine besondere Theorie immaterieller Wesen, die wir sowohl bei Patrizzı wie auch bei MORE finden können.

${ }^{61}$ Div. Dialog, III. 26/27/28. 
sie sehen könntest, wie sie durch züngelnde Lavaflammen taumeln, und wenn du sie hörtest, wie sie in größter Qual brüllen und aus ihrer verstockten Geistesverwirrung und teuflischen Verhärtung heraus Gott gräßlich lästern, so daß sie eine Gemeinschaft von Teufeln der Hölle bilden; ob du nicht, trotz der Traurigkeit dieses tragischen Anblicks, diesen Zustand, und wäre er über die ganze Erde verbreitet, mit der Gerechtigkeit und Güte Gottes vereinbar halten könntest.

Hylobares: Du meinst mit derjenigen Seite seiner Güte, die wir Gerechtigkeit nennen, Philotheus?

Phil. So mag es sein, Hylobares.

Hyl. Davon wurde ich gestern überzeugt, und zwar durch dein Gleichnis von der vergewaltigten Jungfrau und von der gerechten Strafe des Bösewichts, der sie vergewaltigte und so grausam mißbrauchte; daß selbst in solcher Strenge, die durchaus keine Besserung des Bestraften bezweckte, die Zuerteilung der Strafe gleichwohl ihren Ursprung, ihre Gründe und ihr Maß von Gottes Güte herleiten könne.

Phil. Kannst du hieran rückhaltslos festhalten, Hylobares?

Hyl. Ja, gewiß, das scheint mir ein klarer Fall.

Phil. Gut denn, Hylobares, ich habe ein einziges Allheilmittel, das, wenn du es einnehmen willst, aus deinem Geist die tiefsten, letzten und kleinsten Spuren des Zweifels ganz' austreiben wird, den du an Gottes Vorsehung haben kannst, auch wenn der Zustand der Dinge auf Erden noch zehnmal ärger wäre, als ihn Euistor beschrieb.

Hyl. Ich staune, das ist in der Tat etwas, Philotheus. Das wird meine Gedanken über unsere Frage ganz abklären und mich völlig beruhigen. Ich dachte, etwas ganz Wichtiges fehle noch, um meinen Geist ganz zu befriedigen und zu beruhigen: Ich bitte dich, laß es mich dann wissen, Philotheus.

Phil. Es ist einer der beiden berühmten Schlüssel der Vorsehung, und sogar der goldene.

Hyl. Ach, gibt es genau zwei?

Phil. Zwei sind die wichtigsten.

Hyl. Und wenn einer aus Gold, aus was ist bitte der andere? Aus Silber?

Phil. So sagt man.

Hyl. Oh, wie sehne ich mich, daß diese Schlüssel in meine Hand gelegt werden! Bitte, Philotheus, gib sie heraus.

Phil. Nicht, während Bathynous in unserer Gesellschaft ist.

Hyl. Aber warum, Philotheus? Bathynous ist doch gewiß der würdigste unter uns, sie zu empfangen.

Phil. Wenn du alles wüßtest, würdest du freilich so sagen.

Hyl. Bitte, verhehle mir nichts.

Phil. Er war es, der sie zuerst empfing, und das vor vielen Jahren, als er kaum älter war als du selber: Und darum denke keiner von uns, es zieme sich ihm, irgend jemandem diese Schlüssel auszuliefern, während er anwesend ist. Wir behalten ihm diese Ehre vor, der sie als erster empfing.

Hyl. Welch schöne Zeremonie. $\mathrm{O}$ dreimal glückliche Jugend, auf die das strahlende Angesicht der Weisheit so früh geschienen hat! Aber, ich bitte, wo empfing er diese Schlüssel, Philotheus?

Phil. In einem Traum!

Hyl. Was, so ist all mein Hoffen in einen Traum zerflossen? 
Euist. Du weißt, Hylobares, welch hohe Philosopheme im Somnium Scipionis ${ }^{62}$ eröffnet werden.

Hyl. Du hast recht, ich war nur verwirrt, und jetzt erwarte ich nicht weniger Wahrheit und nicht weniger bedeutsame als vorher.

Euist. Bitte, Bathynous, was für eine Art Traum war es? Denn gemäß Macrobius gibt es

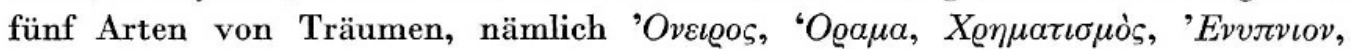
$\Phi \alpha \nu \tau \alpha \sigma \mu \alpha$.

Bath. Im Ernst, Euistor, darüber habe ich seither nie genau nachgedacht.

Euist. Das könntest du mir leicht beantworten, sobald ich dir nur diese verschiedenen Traumarten beschreiben würde.

Hyl. O du aufsässiger Euistor, du würdest uns ganz unnötige Verzögerungen bereiten, nur damit du jetzt dein Geschick in kritischen Haarspaltereien zeigen könntest, während ich inzwischen in übergroßem Begehren fast vergehe, ein so wichtiges «Arcanum» zu erfahren, das meinen Geist in die große, grundlegende Wahrheit einweihen kann, nach der ich so eifrig suche.

Euist. Ich bitte dich, Bathynous, befreie Hylobares von seiner Qual, denn ich sehe, er ist sehr ungeduldig.

Bath. Es ist ein Traum, den ich in meiner Jugend hatte, von einem alten Mann ehrwürdiger Erscheinung und Gebarens, der mit mir im Walde sprach.

Euist. Schon diese Andeutung zeigt, daß es eine Art Traum war, den die Griechen

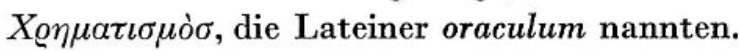

Hyl. Welch gutes Omen, Euistor, dafür danke ich dir. Ich will dir jetzt alle deine kritischen Aufsässigkeiten verzeihen, nur um dieser Bemerkung willen.

Euist. Und ich will mit euch Bathynous bịtten, uns seinen Traum zu erzählen; denn ich bin wohl so begierig wie ihr. Ich freue mich darauf, ein so außergewöhnliches Beispiel eines Traumes kennenzulernen, den wir auf englisch Orakel nennen würden.

Bath. Ich gestehe, meine Herren, ich schäme mich, denn ich werde sehr leichtsinnig erscheinen, wenn ich meine Träume vor Fremden erzähle, besonders vor jemand so ernsthaftem wie Philopolis.

Hyl. Richtig gesprochen ist es kein Traum, Bathynous, sondern ein Orakel.

Bath. Aber ich schäme mich noch mehr, wenn ich behaupte, Orakel zu verkünden und nicht meinen Traum.

Cuphophron: Du verkündest kein Orakel, sondern dir wurde es kundgetan.

Philopolis: Nenn es Traum, Orakel oder Traumorakel, darauf kommt es nicht an, Bathynous, und wir freuen uns, es zu hören. Ich bin nicht so beschränkt noch so grämlich und habe nicht das geringste dagegen, daß jemand seine Träume erzähle, besonders unter diesen Umständen: ja, ich denke, es ist sogar seine Pflicht, es zu tun.

Bath. Gut denn, wenn es sein muß, meine Herren, mit der Erlaubnis von Philopolis und der Ermunterung von Hylobares werde ich euch meinen Traum so kurz und gut wie möglich berichten. Zuerst aber mußt du, Philopolis, wissen, was für ein grüblerischer und gedankenvoller Geist ich von Kindheit an war und welch tiefes und starkes Gefühl der Existenz Gottes mich erfüllte und wie ich früh schon voller Bewußtsein ihm

${ }^{62}$ In Somn. Scip. lib.1. cap. 3. 
mich anvertraute. Und wie, da ich in reiferen Jahren zu denken begann, und einiges wenige von Philosophie eingesogen hatte, ich nicht damit zufrieden war, mir Gott nur in großen Zügen zu denken. Vielmehr begann ich seine Natur schärfer und genauer zu betrachten und sann über seine Attribute nach und verglich sie. So schloß ich vertrauensvoll, teils aus natürlicher Neigung meines Denkens, teils auf Grund der Aussage und Autorität der Heiligen Schrift, daß unendliche Macht, Weisheit und Güte, diese drei, die wichtigsten und begreiflichsten Attribute der göttlichen Natur seien und daß die Güte die herrlichste unter ihnen sei, Krone und Blüte der Gottheit, wenn man so sagen darf, und daß durch sie vor allem der Menschen Seelen göttlich werden. Ohne sie aber würde auch der größte Anteil an den anderen sie nicht göttlich, sondern teuflisch machen.

Da ich im übrigen keine andere Naturwissenschaft noch Metaphysik kannte als die des Volkes und da ich hoffte, daß die Gesetze der äußeren Schöpfung, sei sie sichtbar oder unsichtbar, jener herrlichen und lieblichen Idee der Gottheit entsprechen sollten, einer Idee, die ich mit der größten Frömmigkeit und Herzlichkeit in meinem Busen hegte, so war mein Sinn lange Zeit mit unlösbaren Rätseln und Schwierigkeiten belastet, wie denn die Erscheinungen in der Welt und die volkstümlichen Ansichten mit jenen zwei höchsten Attributen der Gottheit, Weisheit und Güte, zu versöhnen und zu vereinigen seien. Unter solchen Meditationen schloß ich nachts meine Augen, sie grüßten mein Gedenken als erste am Morgen: sie begleiteten meine abgeschiedenen und einsamen Wanderungen durch Feld und Wald, oft so früh, daß dann die meisten andern Sterblichen noch im Bette liegen.

Es geschah daher, Philopolis, daß ich eines Sommermorgens, da ich früher aufgestanden war als gewöhnlich und so lange in einem gewissen Wald (den ich schon länger oft besuchte) gewandert war, daß ich es gut fand, mich am Boden auszuruhen. Da meine Lebensgeister erschöpft waren, teils zufolge der langandauernden körperlichen Bewegung, hauptsächlich aber wegen Schlafmangels und übereifrigen und angespannten Nachdenkens über solche Schwierigkeiten, wie sie Hylobares entweder schon beschrieben hat oder die er, worauf ich schon hinwies, wahrscheinlich noch vorbringen wird; so streckte ich gleich meine müden Glieder zwischen Gras und Blumen am Fuße einer weit ausgebreiteten, grünenden Eiche aus, allwo die sanftfrische Morgenluft im Schatten um meine erhitzten Schläfen spielte. Mit unbeschreiblichem Wohlgefühl erfrischte ich Blut und Lebensgeister, da die fleißigen Bienen emsig um mich über den taufrischen Honigblumen summten. In dieses nahe Geräusch mischte sich gar melodisch das entfernte Singen fröhlicher Vögel, das aus allen Teilen des Waldes widerhallte. Du kannst dir leicht vorstellen, o Philopolis, wie da der ganze Zauber der Natur zusammenwirkte, daß meinen müden Leib bald tiefer Schlaf umfing. Aber meine Seele war doch immer noch wach und träumte offenbar höchst lebhaft, ich wandere noch immer in diesem einsamen Wald, in meinen Gedanken angespannter denn je mit jenen alten Schwierigkeiten der Vorsehung beschäftigt. Aber während ich in dieser großen Anfechtung und geistiger Bedrängnis schwebte und, wie es oft auch im Wachen geschah, heftige und innige Seufzer und Anrufungen zu Gott sandte, erschien plötzlich in einiger Ferne ein sehr ernster und verehrungswürdiger Mann, der langsam auf mich zukam. Er war größer als gewöhnlich. Er war in ein weites, seidenes Gewand purpurner Farbe gekleidet, ähnlich wie 
jene «indischen» Talare, die heute Mode sind; nur waren die Ärmel etwas länger und weiter. Dieses Gewand war mit einem priesterlichen Gürtel zusammengehalten, ebenfalls purpurfarben. Er trug ein Paar sammetene Pantoffeln der gleichen Farbe, aber auf dem Kopfe hatte er einen großen, schwarzen Sammethut, so wie wenn er zugleich Reisender und Bewohner dieser Örtlichkeit wäre.

Cuph. Ich wage es, dir zu versichern, das war das Gespenst eines der edlen Ahnen jener vornehmen Familie, der diese Waldungen gehörte.

Hyl. Du vergissest, Cuphophron, daß Bathynous einen Traum erzählt und daß - und dies zum dritten Male - Gespenster, also Geister, nirgendwo sind und man ihnen daher nicht im Walde begegnen kann.

Philop. Genug damit, Hylobares. Bitte, fahre fort, Bathynous, und beschreibe uns sein Alter und Aussehen, ebensogut wie seine Kleidung.

Cuph. Bitte, mache das, Bathynous: ich höre Dinge wie diese gerne ganz genau berichtet.

Bath. Hätte nicht die Rötlichkeit seiner Haut und die Lebhaftigkeit seines Blickes dagegen gesprochen, die schneeige Weiße seiner Haare, der große Bart und gewisse greisenhafte Züge seines Gesichtes hätten vermuten lassen, er sei etwa hundertzwanzig Jahre alt.

Soph. Darin liegt ja kein Widerspruch, Bathynous: Denn von Moses wird gesagt, er sei hundertzwanzig gewesen, als er starb, doch war sein Auge nicht trübe noch seine Körperkraft geschwunden; doch, bitte, fahre fort.

Bath. Wie er noch entfernter war, stand ich furchtlos und unbewegt, nahm jedoch meinen Hut ab und behielt ihn in der Hand, aus Achtung vor einer so verehrungswürdigen Gestalt. Als er aber näher kam, da erfüllte mich der lebhafte Glanz seiner Augen, die gar durchdringend unter dem Schatten seines schwarzen Hutes hervorblitzten, und sein ganzer Gesichtsausdruck, der doch voll wundervoller Milde und Süße war, mit plötzlichem Schrecken, so daß ich furchtbar zu zittern begann und mich nicht mehr hätte aufrecht erhalten können, wenn er mir nicht seine Hand aufs Haupt gelegt und mir tröstlich zugesprochen hätte. Dies tat er väterlich und sprach: «Gott segne dich, mein Sohn, sei guten Muts und fürchte dich nicht; denn ich bin ein Bote Gottes, um deines Heils willen gesandt. Dein ernstes Mühn und Seufzen nach wahrer Erkenntnis deines Schöpfers und nach den Wegen seiner Vorsehung (dies ist die heilsamste Beschäftigung jedes denkenden Wesens) sind vor Gottes Angesicht emporgestiegen; ich habe den Auftrag, die beiden Schlüssel der Vorsehung in deine Hände zu legen, auf daß du mit ihrer Hilfe die Schatzkammern jener Weisheit aufschließen mögest, die du so eifrig und fromm erstrebst.» Hiemit führte er seine rechte Hand in den linken Ärmel und zog zwei hellglänzende Schlüssel hervor, einer von Silber, der andere von Gold, die durch ein gar schönes himmelblaues Band zusammengeknüpft waren, und legte sie in meine Hände. Ich empfing sie in tiefer Demut und voller Dank für ein so großes Geschenk.

Während dieser Zeit hatte ich mehr als gewöhnliche Kraft und Mut erlangt, was, wie ich bemerkte, mir in wunderbarer Weise durch seine auf mein Haupt gelegte Hand vermittelt worden war, so daß ich eine Art freier Sicherheit und Vertrautheit, mich mit ihm zu unterhalten, erlangte. Darum sagte ich zu ihm, wenn auch mit gebührender Höflichkeit, doch ohne alle Furcht: «Dies ist ein köstliches Paar Schlüs- 
sel, mein Vater, und sehr lieblich anzusehen: Aber wo ist der Schatz, den sie erschließen sollen?» Darauf antwortete er, mich anlächelnd, sogleich: «Die Schätze, mein Sohn, sind in den Schlüsseln selber.» «Dann bedarf ein jeder Schlüssel», sagte ich, «Vater, eines zweiten Schlüssels, ihn aufzuschließen.» «Jeder Schlüssel», sagte er, «mein Sohn, ist sein eigener Schlüssel.» Und damit forderte er mich auf, die Buchstaben zu betrachten, die auf dem silbernen Schlüssel eingeprägt waren, und ein gleiches Kunstwerk war auf dem goldenen zu sehen. Da ich sie nun näher ansah, bemerkte ich, daß die Schlüssel aus einer Gruppe eng aneinander schließender Ringe bestanden und daß die ganzen Schlüssel ganz unregelmäßig und verwirrend mit Buchstaben bedeckt waren.

«Bring die Buchstaben der Schlüssel in die richtige Ordnung», sagte er nun, «und ziehe dann an ihren Griffen, und der Schatz wird herauskommen.» Und ich ergriff den Silberschlüssel; aber obwohl ich die Ringe bewegen konnte, indem ich mit meinen Fingernägeln in die Buchstaben griff, so konnte ich die Buchstaben doch in keine Ordnung bringen, in der sie alle auf geraden Linien gestanden hätten, noch ergab sich irgendein Sinn in irgendeiner Linie. Wie dies der alte Mann sah, sagte er: «Du mußt erst das Motto kennen, mein Sohn, dieses ist der Schlüssel der Schlüssel.» «Ich bitte dich», sagte ich, «o mein Vater, teile mir das Motto mit.» «Das Motto», sprach er, «mein Sohn, ist dies: Claude fenestras, ut luceat domus.» Da ich nun das Motto kannte, versuchte ich aufs neue, und indem ich die dem Motto entsprechenden Buchstaben in eine Linie gebracht hatte, zog ich mit meiner Rechten am Griff, indem ich den unteren Teil in der Linken hielt. Und da kam eine silberne Röhre zum Vorschein, in der eine Rolle war, die meiner Meinung nach aus dünnem Papier bestand, die aber so stark wie jedes Pergament und weiß wie neuer Schnee war.

Diese Rolle nun erkühnte ich mich zu öffnen. Sie war völlig quadratisch, auf allen Seiten mit gleichbreitem Rand, der mit Linien in himmelblauer Farbe ausgezogen war, höchst vollkommen und lieblich. In der Mitte war das Bild der Sonne in blendendem Gold! Um die Sonne waren sechs Kreise mit ebenso blauen Linien gezogen. Zwei dieser Kreise waren sehr nahe beim Sonnenkörper, die vier anderen waren von ihm und untereinander weiter entfernt. Auf jedem dieser Kreise war ein kleiner Fleck, wie eine Kugel, aber in zwei verschiedenen Farben; die eine Seite gegen die Sonne glänzend wie Silber, die andere von trübem, mißfarbenem Schwarz. Um die kleinen Kugeln im dritten und fünften Kreis waren kleine blaue Kreise gezeichnet, einer um die dritte und vier um die fünfte: und auf jedem dieser Kreise war wieder ein kleiner, kugelartiger Fleck, von kleinerer Größe als der in der Mitte. Es war auch etwas um die Kugel auf dem sechsten Kreis, aber daran erinnere ich mich nicht mehr so genau. Außerhalb dieser Kreise war eine unzählbare Schar sternartiger, goldener Figuren, von ähnlichem Glanze wie der der Sonne, aber weniger stark, die, zufällig verstreut, teils entfernt vom Rand, teils nahe bei diesem, teils von diesem durchschnitten waren, so, als ob angedeutet werden sollte, daß ihrer noch viel mehr seien bis zu unbestimmten Fernen. Dieser Plan unterhielt meine staunenden Augen eine gute Weile; denn dergleichen hatte ich noch nie gesehen, und ich war entschlossen, seine Linien fest in mein Gedächtnis zu prägen, damit ich mich später mit jenem verehrungswürdigen Manne desto leichter darüber unterhalten könne. Denn ich kannte den Sinn der Zeichnung der Inschrift am oberen Rande wegen, die lautete: 
«Das wahre Weltsystem ${ }^{63}$ ». Indem ich mich so befriedigt hatte, rollte ich die Rolle wieder auf, versorgte sie in der silbernen Röhre und schob diese ohne Mühe in den unteren Teil des Schlüssels. Und indem ich die Linie von Buchstaben, die das Motto enthielt, wieder verstellte, war alles sicher wie vorher abgeschlossen.

Nachdem mich die Eröffnung des ersten Schatzes so gefreut hatte, war ich desto begieriger, auch den zweiten zu gewinnen; und da ich wußte, daß jeder Versuch umsonst wäre ohne die Kenntnis des Mottos oder «des Schlüssels des Schlüssels», so ersuchte ich diesen göttlichen Weisen, es mir mitzuteilen. «Das werde ich gerne tun, mein Sohn», sprach er: «und ich bitte dich, nimm es wohl in acht. Es lautet: Amor Dei Lux Animae.» «In der Tat: ein herrliches Motto», sagte ich. «Dieses Motto ist an sich selber ein Schatz.» Doch machte ich mich ans Werk wie zuvor, und indem ich die Buchstaben so ordnete, daß eine ihrer Linien das Motto klar enthielt, zog ich an beiden Enden des goldenen Schlüssels, so wie ich es am silbernen getan hatte, und in einer goldenen Röhre, die im Griff des Schlüssels eingelassen war, fand ich eine Rolle aus feinem Papier, wie man es nennen kann, sehr weiß und rein, das, obwohl sehr dünn, durchaus nicht durchscheinend war. Die Beschriftung war wieder auf allen Seiten von einem gleichmäßigen Rand begrenzt. Nur war dieser viel prächtiger, reich geziert mit Blumengewinden in Gold, Karmin und Blau. Und ich sah daß zwölf in goldenen Buchstaben geschriebene Sätze die ganze Fläche füllten. Der erste Satz war:

Das Maß der Vorsehung ist die göttliche Güte, die nur in sich selber beschränkt und unendlich ist.

2. Der Faden der Zeit und die Ausdehnung des Universums: die gleiche Hand hat jenen gesponnen und breitete diese aus.

3. Dunkelheit und Abgrund waren vor dem Licht und Sonnen oder Sterne vor jeder Undurchsichtigkeit oder jedem Schatten.

4. Alle denkenden Geister, die je waren, sind oder sein werden, entsprangen mit dem Licht und jubelten vor Gott im Schöpfungsmorgen.

5. Angesichts der unzählbaren Scharen freier Wesen, Gestalter ihres eigenen Schicksals, wäre es ein Wunder gewesen, wenn alle denselben Weg beschritten hätten. Und darum reichten sich schließlich Sünde und Undurchsichtigkeit die Hände.

6. So wie das Licht den Schatten übertrifft, so übertreffen auch die Gegenden des Glücks jene von Sünden und Elend.

${ }^{63}$ Das Bild des «wahren Weltsystems» entspricht der Abbildung im dritten Teil der Principia Philosophiae Descartes', was im späteren Verlaufe des Gesprächs auch festgestellt wird. - Der sechste Planet ist der Saturn. Zur Zeit, da Mone seinen Dialog schrieb, wußte er noch nicht, was sich um den Saturn befinde. GaliLEI hatte zwar den Ring gesehen, aber sein primitives Fernrohr zeigte ihn nur undeutlich. Es schien ihm, als lehnten sich an den Planeten rechts und links zwei kleine Begleiter, die zeitweise verschwanden, um dann wieder in Erscheinung zu treten. Später schien es ihm, als ob der Saturn beidseitig zwei Mützen oder Ohren trüge, die in der Mitte einen schwarzen Fleck zeigten (Brief Galileis an Benedetto Castelli, 28. August 1640). - Erst Christian Huygens erkannte, daß es sich um einen Ring um den Saturn handelt (Systema Saturnium, Haag 1669). 
Diese sechs, Philopolis, erinnere ich genau, aber ich hatte alle zwölf mit meinen Augen überflogen: Doch nachher ging ich sie der Reihe nach genau durch, um sie alle genau in mein Gedächtnis einzuprägen (denn ich erwartete nicht, daß ich die Schlüssel mit nach Hause nehmen dürfe), und wie ich bis zum sechsten Aphorismus gelangt war, waren zwei Esel hinter mir aus dem Wald gekommen, einer auf der einen, der andere auf der anderen Seite des Baumes, und diese begannen so laut und roh zu schreien, daß sie mich nicht nur weckten, sondern mir überdies in grausamer Art klarmachten, daß ich die ganze Zeit nur geträumt hatte. Denn jener alte, ernste Mann, die silbernen und goldenen Schlüssel und herrlichen Pergamente, alle verschwanden plötzlich, und ich fand mich am Fuße jener Eiche sitzend, unter der ich eingeschlafen war, zwischen zwei roh schreienden Eseln.

Euist. Das ist die gewöhnliche Erfahrung, Bathynous, die man mit diesen Tieren macht. So geschah es der Nymphe Lotis ${ }^{64}$, die in einer Mondscheinnacht fest im Grase schlief und durch das laute Brüllen von Silens Esel geweckt wurde. Esel scheinen die Trompeter der Wälder zu sein, Bathynous, die sorglose Menschen aus tiefem Schlafe wecken.

${ }^{64}$ Die Nymphe Lotis wird von Priapos verfolgt, der sie im Schlaf überrascht. Der Esel des Silen weckt sie durch sein Geschrei, worauf ihn Priapos erschlägt. Der Esel wird schließlich unter die Sterne versetzt. Ovid, Fast. 1, $393 \mathrm{ff}$. 